\title{
Enzymatic Degradation of Cortical Perineuronal Nets Reverses GABAergic Interneuron Maturation
}

\author{
Ashleigh Willis ${ }^{1}$ Judith A. Pratt ${ }^{2} \cdot$ Brian J. Morris $^{1}$
}

Received: 26 October 2021 / Accepted: 16 February 2022 / Published online: 1 March 2022

(c) The Author(s) 2022

\begin{abstract}
Perineuronal nets (PNNs) are specialised extracellular matrix structures which preferentially enwrap fast-spiking (FS) parvalbumin interneurons and have diverse roles in the cortex. PNN maturation coincides with closure of the critical period of cortical plasticity. We have previously demonstrated that BDNF accelerates interneuron development in a c-Jun- $\mathrm{NH}_{2}-$ terminal kinase (JNK)-dependent manner, which may involve upstream thousand-and-one amino acid kinase 2 (TAOK2). Chondroitinase-ABC (ChABC) enzymatic digestion of PNNs reportedly reactivates 'juvenile-like' plasticity in the adult CNS. However, the mechanisms involved are unclear. We show that ChABC produces an immature molecular phenotype in cultured cortical neurons, corresponding to the phenotype prior to critical period closure. ChABC produced different patterns of PNN-related, GABAergic and immediate early (IE) gene expression than well-characterised modulators of mature plasticity and network activity $\left(\mathrm{GABA}_{\mathrm{A}}-\mathrm{R}\right.$ antagonist, bicuculline, and sodium-channel blocker, tetrodotoxin (TTX)). ChABC downregulated JNK activity, while this was upregulated by bicuculline. Bicuculline, but not ChABC, upregulated $B d n f$ expression and ERK activity. Furthermore, we found that BDNF upregulation of semaphorin-3A and IE genes was TAOK mediated. Our data suggest that $\mathrm{ChABC}$ heightens structural flexibility and network disinhibition, potentially contributing to 'juvenile-like' plasticity. The molecular phenotype appears to be distinct from heightened mature synaptic plasticity and could relate to JNK signalling. Finally, we highlight that BDNF regulation of plasticity and PNNs involves TAOK signalling.
\end{abstract}

Keywords c-Jun N-terminal kinase (JNK) - Extracellular matrix · TAOK2 - Brain-derived neurotrophic factor (BDNF) · Bicuculline $\cdot$ Synaptic plasticity $\cdot$ Glycoprotein biosynthesis

\section{Introduction}

Perineuronal nets (PNNs) are complex extracellular matrix structures which preferentially surround the soma, proximal dendrites and axonal nodes of Ranvier of specific neuronal subtypes [1-5]. These nets are predominantly found around fast-spiking parvalbumin (PVB) interneurons [6], although a small number of exceptions have been reported (notably, a subset of somatostatin (SST) interneurons which express Kv3 potassium channels [7] and a population of glutamatereactive neurons which are surrounded by diffuse PNNs [8]).

Brian J. Morris

brian.morris@glasgow.ac.uk

1 Institute of Neuroscience and Psychology, College of Medical Veterinary and Life Sciences, University of Glasgow, Glasgow G12 8QQ, UK

2 Strathclyde Institute of Pharmacy and Biomedical Sciences, University of Strathclyde, Glasgow G4 ORE, UK
PNNs possess a sophisticated molecular composition, with some work indicating heterogeneity of these structures across brain regions and cell types [9, 10]. Nonetheless, it appears that PNNs share a basic molecular composition [5]. Structurally, PNNs are composed of a hyaluronic acid (HA) backbone which is enriched with chondroitin sulphate proteoglycans (CSPGs; predominantly aggrecan (Acan/ACAN), brevican (Bcan/BCAN), neurocan (Ncan/NCAN) and versican $(V c a n / V C A N))$ bound via glycosaminoglycan sidechains [5, 11-13]. PNNs are stabilised by tenascin-R (TN-R) and hyaluronan and proteoglycan link proteins (HAPLNs; predominantly HAPLN1 and 4) [14, 15]. Differential sulphation patterns of CSPGs can act also as binding sites for specific molecules, including axonal and neurite guidance cue semaphorin-3A (SEMA3A) [16].

PNNs have been linked to synaptic plasticity [17-19] and facilitation of fast-spiking activity [20, 21]. PNN formation is proposed to be activity dependent [22] and these structures play a significant role in cortical maturation. During 
development, PNNs increase in density and form 'tighter' nets around PVB interneurons. Incidentally, this 'tightening' of PNNs coincides with the closure of the critical period of cortical plasticity [23]. Essentially, it appears less dense PNNs infer a more permissive structural state which enables heightened synaptic plasticity $[17,24,25]$. As these nets condense, structural and functional plasticity is restricted [26]. Indeed, PNNs have been proposed to act as a molecular 'brake' which inhibits excessive plasticity and contributes to the closure of the critical period.

Transgenic models which knock out specific PNN components attenuate PNN formation, although the effect on PNN ablation appears to be dependent on the targeted component and, in some cases, is dose dependent. For example, conditional Acan knockout entirely ablates PNN formation [27], while mice heterozygous for Acan display anatomically normal PNNs [28]. Tenascin-R (TN-R) knockout mice present distinctly 'fuzzy' or granular PNNs which lack proximal dendrite coverage [28]. HAPLN1 knockout mice also show attenuated PNNs [29]. Interestingly, Bcan knockout mice do display Wisteria floribunda agglutinin (WFA) lectin-reactive PNNs (a widely used marker for PNNs) [28, 30]. These mice present long-term potentiation deficits, but show no overt deficits in learning or memory behaviours [31]. The intricacies of specific PNN component contribution to formation and function are yet to be fully understood. However, it is clear that CNS wide loss of PNN structures appears to produce functional consequences which can affect learning and memory behaviours, potentially due to their modulation of synaptic plasticity and axonal transduction $[3,27,29,30]$.

PNNs can be manipulated more locally via enzymatic digestion. One popular method of enzymatic digestion employs Chondroitinase $\mathrm{ABC}$ (ChABC; a bacterial enzyme derived from Proteus vulgaris). ChABC application in vitro and in vivo has proved successful in depleting PNNs, as assessed by the lack of WFA labelling. ChABC effects owe mainly to the enzyme's ability to degrade sugar chains from CSPGs [32-34]. Only HAPLN1 remains bound to the cell surface following ChABC treatment [35].

Manipulation of PNNs by ChABC in the mature brain has gathered much attention due to reports which indicate that PNN digestion in vivo may be able to recapitulate a form of juvenile plasticity [24]. Additional work has shown that injection of $\mathrm{ChABC}$ to the primary visual cortex can facilitate structural and functional recovery of normal ocular dominance in rats which were subjected to a period of monocular deprivation [36]. ChABC appears to elevate the motility of cortical spines, and confers on them a higher degree of functional and structural plasticity [26]. Moreover, targeting $\mathrm{Ch} \mathrm{ABC}$ to axons promotes neurite outgrowth and axonal spouting [37], further suggesting that PNN degradation can induce a state of heightened structural plasticity [38].
Considerable research efforts have focused on the modulation of synaptic plasticity after ChABC application, along with the effects on learning, memory and cognition [34, 39-42]. However, less is understood about the molecular phenotype induced. In particular, it is unclear how PNN attenuation via $\mathrm{ChABC}$ modulates the expression of genes which encode critical PNN components. To our knowledge, understanding how this manipulation impacts GABAergic and plasticity-related gene expression also remains ill-defined.

Here, we sought to define the molecular phenotype induced by ChABC digestion of PNNs. Moreover, we aimed to investigate whether 'juvenile-like' plasticity induces an immature molecular phenotype, and how this phenotype may differ from 'classically' induced mature homeostatic plasticity.

To this end, we treated primary cortical neuronal cultures with ChABC and measured expression of a variety of PNNrelated, GABAergic, immediate early (IE) and developmentally regulated genes. We contrasted these with the results from primary neuronal cultures treated with known modulators of mature homeostatic plasticity, synaptic scaling and network activity; $\mathrm{GABA}_{\mathrm{A}}$-receptor antagonist, bicuculline, and sodium channel blocker, tetrodotoxin (TTX).

The downstream effects of ChABC-induced PNN digestion on intracellular signalling have not been fully investigated. We have previously demonstrated modulation of PNN density and gene expression by brain-derived neurotrophic factor (BDNF) and c-Jun- $\mathrm{NH}_{2}$-terminal kinase (JNK) signalling. This work has shown that BDNF accelerates cortical interneuron maturation in vitro, and highlights that many BDNF effects on PNN development rely on appropriate JNK function and, potentially, upstream activator thousand-andone amino acid kinase 2 (TAOK2). BDNF appears to be involved in the closure of the critical period [43-45] and is another known modulator of synaptic transmission and plasticity which has potent effects at adult synapses in multiple regions of the CNS [46].

Considering this, we investigated the effects of $\mathrm{ChABC}$, bicuculline and TTX on MAPK signalling activity (via JNK and extracellular signal-regulated kinase (ERK) phosphorylation), along with expression of Bdnf and Taok2. Finally, we assessed whether TAOK signalling was involved in the effects of exogenous BDNF treatment on PNN-related, GABAergic and IE gene expression.

\section{Experimental Procedures}

\section{Primary Neuronal Culture}

Primary cortical neuronal cultures (which contain a mixture of neuronal cell types, including pyramidal cells and 
interneurons) were obtained from C57BL/6 mouse embryos at E17 and prepared according to our previously outlined procedures [47]. Briefly, pregnant mothers were euthanised (cervical dislocation) and embryos were removed immediately from the uterus. Cortices were dissected in ice-cold Hanks Balanced Salt Solution (HBSS), meninges removed and transferred into fresh HBSS. Cortical tissue was then finely homogenised, washed twice in HBSS and incubated in $0.05 \%$ trypsin/EDTA at $37^{\circ} \mathrm{C}$ for $10 \mathrm{~min}$. DMEM (supplemented with $10 \% \mathrm{HI}$ horse serum, $1 \%$ penicillin-streptomycin, $1 \%$ Glutamax) was added to inactivate trypsin and tissues were subjected to centrifugation at $1500 \mathrm{rpm}$ for 5 min at $4{ }^{\circ} \mathrm{C}$. Following gentle trituration and resuspension, DMEM ( $9 \mathrm{ml} / \mathrm{embryo}$ ) was added and neurons were seeded into polystyrene-based plastic plates which were pre-coated with $4 \mu \mathrm{g} / \mathrm{ml}$ poly-D-lysine and $6 \mu \mathrm{g} / \mathrm{ml}$ laminin. Neurobasal medium supplemented with B27 was added prior to cell seeding and allowed to equilibrate to incubator conditions for $30 \mathrm{~min}\left(37^{\circ} \mathrm{C}, 5 \% \mathrm{CO}_{2}\right)$. Cells were seeded at a $50 \%$ dilution. Half-volume media changes with Neurobasal/B27 were performed at 24 and $48 \mathrm{~h}$ following seeding. Subsequently, $50 \%$ medium changes with Neurobasal/B27 were made every 3-4 days. For the present work, cells were allowed to mature for at least 14 days in vitro (DIV) prior to enzymatic or pharmacological treatment.

\section{Culture Treatments}

For enzymatic degradation of PNNs, cultured cortical neurons were treated with small volumes of either vehicle (50 mM Tris- $\mathrm{HCl} / 60 \mathrm{mM}$ sodium acetate/0.02\% BSA, $\mathrm{pH}$ 8.0) or ChABC ( $30 \mathrm{mU} / \mathrm{ml})$ at 18 DIV for 3 DIV (treatment terminated at $21 \mathrm{DIV})$. Optimal ChABC concentration and treatment length were determined with reference to previous reports of in vitro use of the enzyme [22, 48]; suitable concentration confirmed via our own concentration gradient experiments (10, 30 and $100 \mathrm{mU} / \mathrm{ml}$; Fig. S1).

To assess effects of the $\mathrm{GABA}_{\mathrm{A}}$ receptor antagonist bicuculline [49] and the sodium channel blocker tetrodotoxin (TTX) [50] on gene and protein expression, cortical cultures were treated with either vehicle $\left(\mathrm{dH}_{2} \mathrm{O} /\right.$ citrate buffer $(0.1 \mathrm{M}$ citric acid monohydrate $/ 0.1 \mathrm{M}$ tri-sodium citrate, $\mathrm{pH}$ 4.8)), $50 \mu \mathrm{M}$ bicuculline [49, 51-53] $\left(\mathrm{dH}_{2} 0\right)$ or $2 \mu \mathrm{M}$ TTX [54] (citrate buffer, $0.1 \mathrm{M}$ citric acid monohydrate/ $0.1 \mathrm{M}$ tri-sodium citrate, $\mathrm{pH} 4.8$ ) for $16 \mathrm{~h}[55,56]$ at 20 DIV (treatment terminated at 21 DIV).

To investigate the consequence of BDNF on PNN, GABAergic and IE gene expression, along with the reliance of any effects on TAOK, cells were treated with either vehicle ( $\mathrm{dH}_{2} \mathrm{O} / \mathrm{DMSO}$ ), $30 \mu \mathrm{M} \mathrm{CP}-43$ [57, 58] (TAOK inhibitor in DMSO), $50 \mathrm{ng} / \mathrm{ml} \mathrm{BDNF}$ [59] $\left(\mathrm{dH}_{2} 0\right)$ or CP-43 + BDNF (30 $\mu \mathrm{M}$ and $50 \mathrm{ng} / \mathrm{ml}$, respectively) at 14 DIV for 7 days (treatment terminated at 21 DIV).

\section{Immunofluorescent Labelling}

Subsequent to ChABC-induced PNN degradation experiments, cells were fixed with $4 \%$ paraformaldehyde for $30 \mathrm{~min}$ on ice. Cells were permeabilised and blocked with PBS $(0.3 \mathrm{M} \mathrm{NaCl}) / 0.5 \%$ Triton $\mathrm{X}-100 / 10 \%$ normal goat serum (NGS) for $1 \mathrm{~h}$ at room temperature. Following this, cells were incubated overnight in a humidified chamber with primary antibodies diluted in $0.3 \mathrm{M} \mathrm{PBS} / 0.5 \%$ Triton X-100/3\% NGS at $4{ }^{\circ} \mathrm{C}$. Cells were double labelled with anti-somatostatin (SST, ab183855, Abcam, 1:250) and biotinylated Wisteria floribunda agglutinin (WFA, B-1355-2, Vector Laboratories; 1:2000) lectin, which labels PNNs via preferential binding of glycans containing terminal $\mathrm{N}$-acetylgalactosamine $\beta 1$ residues on the chondroitin sulphate chains which compose these nets $[6,60]$. Following primary antibody incubation, cells were washed three times (0.3 M PBS, $5 \mathrm{~min} /$ wash). Cells were incubated in appropriate secondary antibodies diluted in $0.3 \mathrm{M} \mathrm{PBS} / 3 \%$ NGS for $1 \mathrm{~h}$ in the dark; for anti-SST, Alexa488-anti-rabbit (1:300; Jackson ImmunoResearch) and for WFA, streptavidin-conjugated Rhodamine Red-X (1:500; Jackson ImmunoResearch). Cells were washed a final three times before Vectashield mounting (Vector Laboratories, H-1200).

Prepared samples were visualised with a $\times 40$ oil-immersion lens (Nikon). Confocal microscopy (BioRad, MRC 1024) was used to obtain Z-stacks (scanning $8-\mu \mathrm{m}$ planes, $0.5-\mu \mathrm{m}$ intervals). All settings were kept constant across related images. Projection images (summed z-stacks) were produced and used for subsequent qualitative analysis and representative images.

\section{RNA Isolation, CDNA Synthesis and Reverse Transcription-Quantitative PCR (RT-qPCR)}

RNA isolation was performed using RNeasy mini-kits according to the manufacturers' protocol (Qiagen, 74,104). RNA concentrations were normalised and cDNA was synthesised using high-capacity RNA to cDNA kit (ThermoFisher Scientific, 43,874,060) (including corresponding noRT condition for each synthesis reaction).

RT-qPCR primers were designed using NCBI primer blast in combination with Ensembl and obtained from Sigma. Sequences for all primer pairs are in contained Table S1. All primers were validated for product size and specificity via gel electrophoresis and visualisation. All primers were amplified within 90-110\% efficiency (Fig. S2). Primers were diluted to $10 \mu \mathrm{M}$ prior to use and RT-qPCR was performed using Fast SYBR Green Master Mix (Applied Biosystems, $4,309,155$ ) in $20-\mu 1$ reactions (ABI Prism). Cycle timesstep 1: $50{ }^{\circ} \mathrm{C}, 2 \mathrm{~min}$ ( 1 cycle); step 2: $95^{\circ} \mathrm{C}, 2 \mathrm{~min}$ (1 cycle); step 3: $95^{\circ} \mathrm{C}, 10 \mathrm{~s}, 60^{\circ} \mathrm{C}, 30 \mathrm{~s}$ ( 40 cycles). 
a
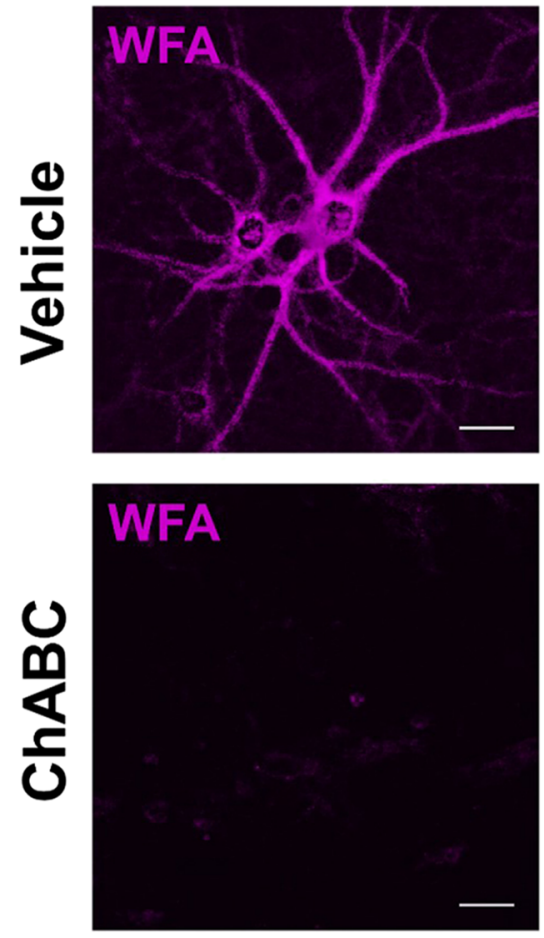

b

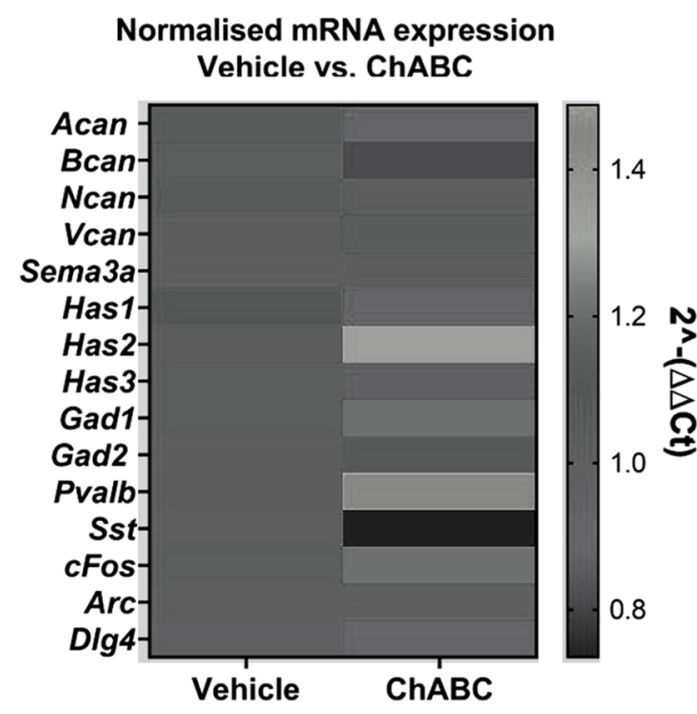

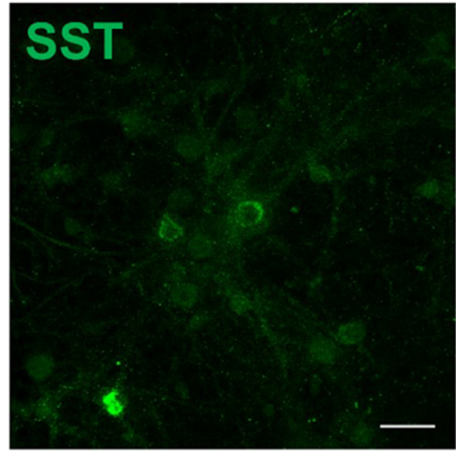

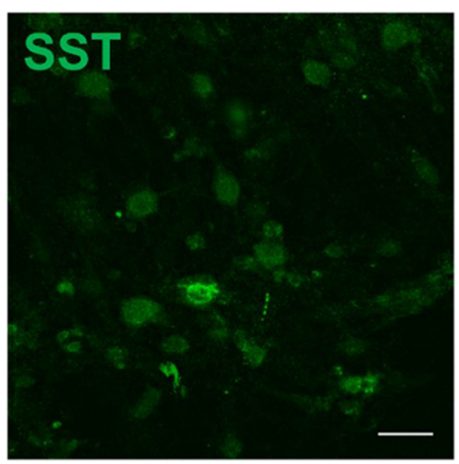

C

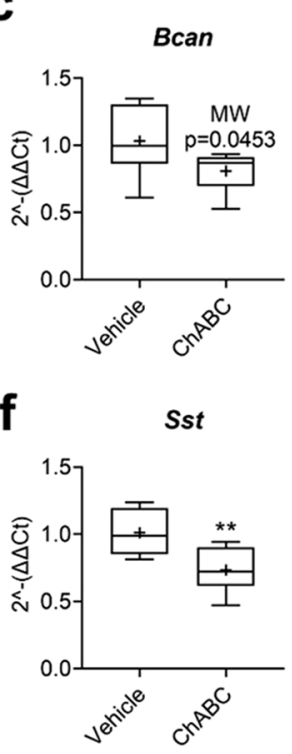

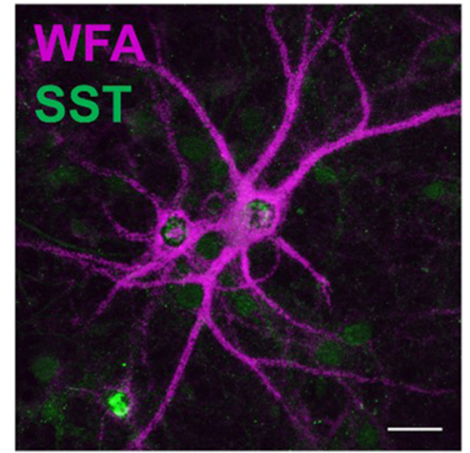

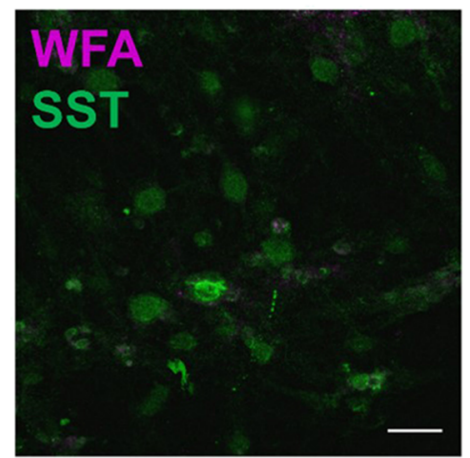

e

d

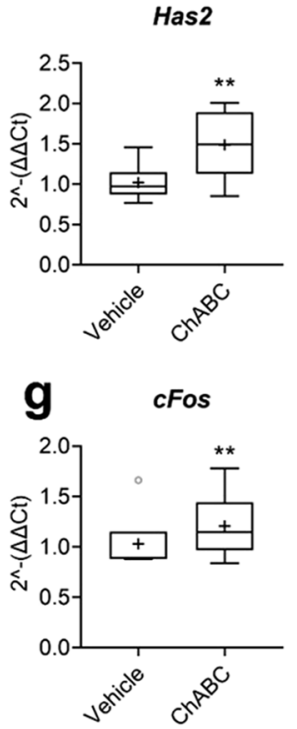

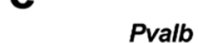

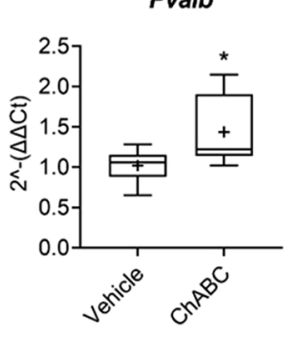

Relative expression of each target gene was calculated via $\Delta \Delta \mathrm{Ct}$ method using Gapdh or Tbp as a housekeeping gene, selected based on stable expression across all experimental conditions. Housekeeping genes used for specific experiments can be found in corresponding figure legends.

\section{Protein Extraction}

Protein from primary cortical neuronal cultures was extracted in line with our previously published protocols
[61]. In brief, culture medium was removed, plates were placed on ice and $1000 \mu \mathrm{l}$ of ice-cold PBS (pH 7.5) was added for 15-30 s. Upon wash buffer removal, $80 \mu \mathrm{l}$ of RIPA buffer (10 nM Tris-HCl, $150 \mathrm{mM} \mathrm{NaCl}, 1 \mathrm{mM}$ EGTA, $0.5 \%$ NP40, $0.1 \%$ SDS, $0.1 \%$ sodium deoxycholate) was added. Cells were lysed briefly, after which wells were manually scraped ( $30 \mathrm{~s} /$ well $)$ and contents were removed within $10 \mathrm{~min}$. Extracts were centrifuged at 13,000 rpm for $10 \mathrm{~min}$ at $4{ }^{\circ} \mathrm{C}$. Subsequently, supernatants were collected and protein concentration determined via Bradford protein 
४Fig. 1 In vitro ChABC degradation of PNNs dysregulated GABAergic and PNN-related gene expression, while upregulating $c F o s$ expression. a Representative images of primary cortical neuronal cultures treated with either vehicle or ChABC $(30 \mathrm{mU} / \mathrm{ml})$ from 18 to 21 DIV. Cultures were labelled with anti-SST (green) and WFA (magenta). A distinct lack of PNN structures was qualitatively observed in cultured treated with ChABC. $N=5$ independent cultures. Scale bars $=30 \mu \mathrm{m}$. Expression of key PNN-related, GABAergic and immediate-early genes were measured via RT-qPCR. b Heatmap of mean normalised mRNA expression of neurons treated with either vehicle or ChABC from 18 to 21 DIV (30 mU). RNA was isolated and cDNA synthesised at 21 DIV. Only genes showing a statistically significant change in expression are further presented as boxplots. c, d Compared to vehicle, ChABC downregulated Bcan expression (Mann-Whitney: $\mathrm{CI}(0.013,0.48), p=0.045)$, while Has 2 was significantly upregulated $(p=0.038)$. e, f An opposing change was found in Pvalb and Sst in response to ChABC treatment, with the upregulation of Pvalb $(p=0.044)$ and downregulation of Sst $(p=0.019)$. $\mathrm{g}$ A moderate increase in $c F o s$ expression was observed $(p=0.043)$. There were no significant changes in expression of other CSPGs or PNN-related genes. Gad1, Gad2, Dlg4 and Arc expression were also not significantly affected by ChABC treatment. Relative expression was calculated using $\Delta \Delta \mathrm{Ct}$ method with Gapdh housekeeping gene. $N=10$ independent samples derived from 3 independent cultures. Data are presented as boxplots with medians, interquartile ranges and 'Tukey' whiskers; crosses indicate sample means. Data were analysed via one-way ANOVA with Tukey post hoc multiple comparisons. * and $* *$ represent Tukey post hoc significance compared to vehicle ( $p<0.05$ and $p<0.01$, respectively). In addition, a Mann-Whitney $U$ test was performed for vehicle vs. ChABC on Bcan

assay [62]. Samples were stored at $-80{ }^{\circ} \mathrm{C}$ for downstream analysis.

\section{Protein Electrophoresis and Western Blot}

For each sample, $50 \mu \mathrm{g}$ of protein was prepared with $4 \times$ sample buffer (NuPAGE, Novex, NP0007) and sample reducing agent (NuPAGE, Novex, NP0004) prior to denaturation $\left(80{ }^{\circ} \mathrm{C}\right.$ for $\left.10 \mathrm{~min}\right)$. Samples were then subjected to SDS-PAGE in $10 \%$ Bis-Tris gels $(120 \mathrm{~V}, 2 \mathrm{~h})$ and transferred to PVDF membranes (30 V, $1 \mathrm{~h}$ ). Sample loading order was alternated across individual gels to ensure conditions were not systematically run in the same location of the gel. Following transfer, membranes were washed twice in $\mathrm{dH}_{2} \mathrm{O}$ and blocked for $30 \mathrm{~min}(0.5 \%$ Tween-Tris-buffered saline (TTBS) $+3 \%$ dried milk). Membranes were incubated in primary antibodies overnight at $4{ }^{\circ} \mathrm{C}$ with agitation (pJNK: Abcam, ab76572, 1:12,000; pERK; CST, \#4377, 1:5000, diluted in SignalBoost Immunoreaction Enhancer solution (Millipore, 407,207)). Following incubation, membranes were washed ( $3 \times$ TTBS, $10 \mathrm{~min}$ ) and incubated in HRP-conjugated anti-rabbit secondary antibody $(1: 10,000$, Sigma-Aldrich, 12-348) for $2 \mathrm{~h}$. Membranes were washed again (once TTBS, twice $10 \times$ TBS) prior to imaging. Blots were further probed with HRP-conjugated GAPDH antibody (1:20,000, Genetex, GTX627408-01). Membrane-bound antibodies were detected via a chemiluminescent HRP substrate (Immobilon, Millipore, WBKLS0100), and digital images were captured via PXi4 (Syngene).

Quantification of digital images was performed in ImageJ, with band intensity values measured and normalised to GAPDH. Normalised data were expressed as a percentage of vehicle mean.

\section{Data Analysis}

Data were analysed via one-way ANOVA with Tukey post hoc multiple comparisons or, when required, Mann-Whitney $U$ tests (Minitab 17). Results were considered significant if $p<0.05$. Details of specific analysis for particular experiments can be found in corresponding figure legends. A complete table of statistics ( $F$ and $p$ values) can be found in Table S2. Boxplots and heatmaps were produced in Prism 9.

\section{Results}

\section{ChABC-Induced PNN Degradation Dysregulated Key PNN-Related, GABAergic and Immediate Early (IE) Gene Expression}

Our initial experiments sought to understand the consequences of ChABC-induced PNN degradation on expression of key PNN, GABAergic and immediate early (IE) genes. Using double immunofluorescent labelling with WFA lectin and anti-SST, we confirmed successful PNN ablation in primary neuronal cultures treated at $18 \mathrm{DIV}$ with either vehicle or ChABC (30 mU/ml) for 3 DIV (Fig. 1a). As aforementioned, while PNNs primarily enwrap PVB-expressing interneurons, these structures have been shown to localise around a small subset of SST-expressing interneurons which express voltage-gated potassium channel subunit Kv3 [7, 63]. Technical limitations encountered with PVB immunofluorescent labelling in vitro led us to co-label with SST. Our qualitative assessment of cultures revealed clear WFA + I $\mathrm{SST}+$ and WFA + /SST - labelling in vehicle-treated cultures; no WFA + /SST + or WFA + /SST - was found in any ChABC-treated cultures, indicating successful enzymatic digestion of PNNs (Fig. 1a and Fig. S1).

RT-qPCR analysis of gene expression revealed a distinct downregulation of Bcan (Fig. 1c), a CSPG which is prevalent throughout the mature PNN structure but is thought to be enriched around the axonal initial segment [64, 65], after ChABC treatment. We found no significant changes in any other CSPG components of PNNs (Fig. 1b). However, compared to vehicle, membrane-bound Has 2 which is one of three enzymes (HAS1-3) that synthesise the hyaluronan backbone upon which CSPGs bind, was upregulated after ChABC treatment (Fig. 1d). 
Our results also indicated dysregulation to two dominant and distinct interneuron subtypes following $\mathrm{ChABC}$ treatment. RT-qPCR revealed a significant upregulation in $P$ valb expression and simultaneous downregulation of Sst in cultures treated with $\mathrm{ChABC}$, compared to vehicle (Fig. 1e, f). In addition, our data indicate a substantial upregulation in cFos (Fig. 1g), an IE gene which, while not a specific marker for GABAergic interneurons, is widely used as a functional marker of neuronal activity [66].

\section{GABAA Antagonist, Bicuculline, Upregulated Acan and Immediate Early (IE) Gene Expression}

Our data indicate a dysregulation to expression of key PNN components (Bcan and Has2, both of which are developmentally regulated and have been implicated in synaptic plasticity and stability [31, 67-69]), cFos, Pvalb and Sst. These changes indicate a potential dysregulation of inhibitory interneuron dynamic, network activity and, potentially, synaptic plasticity. Our following experiments investigated consequences of two known modulators of excitatory-inhibitory balance, network activity, synaptic scaling and plasticity: $\mathrm{GABA}_{\mathrm{A}}$ antagonist bicuculline and sodium channel blocker tetrodotoxin (TTX). To this end, primary cortical neuronal cultures were treated with either vehicle, bicuculline $(50 \mu \mathrm{M})$ or TTX $(2 \mu \mathrm{M})$ for $16 \mathrm{~h}$ prior to RNA isolation at $21 \mathrm{DIV}$.

RT-qPCR revealed a clear upregulation of Acan in response bicuculline, but not TTX, treatment (Fig. 2b). In addition, compared to vehicle, bicuculline substantially increased expression of both Arc and $c F o s$, whereas $c F o s$ expression was reduced in TTX-treated cultures (Fig. 2f, g). Arc expression was also significantly lower in TTXtreated cultures compared to those treated with bicuculline (Fig. 2f). Our data also showed a significant downregulation of Dlg4 (PSD-95) in bicuculline-treated cultures compared to vehicle (Fig. 2e). a

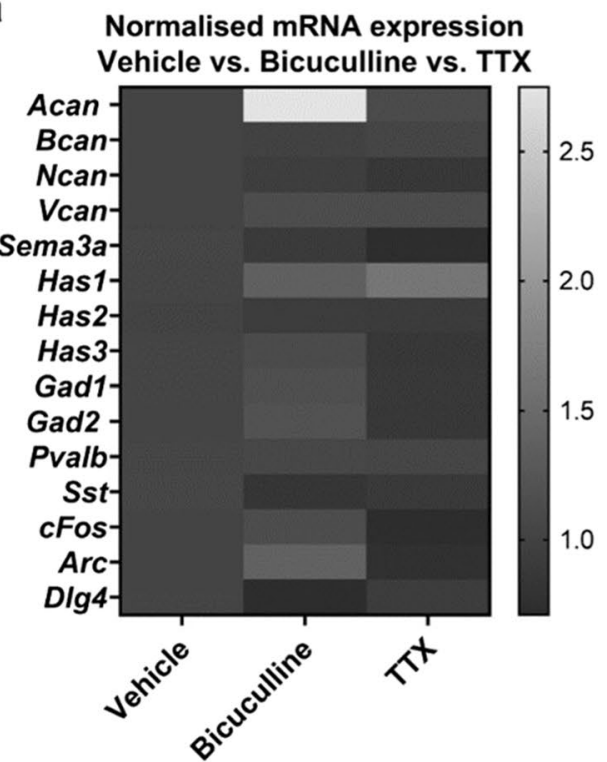

b

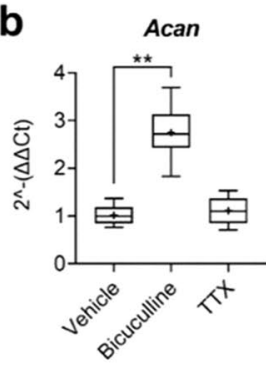

e

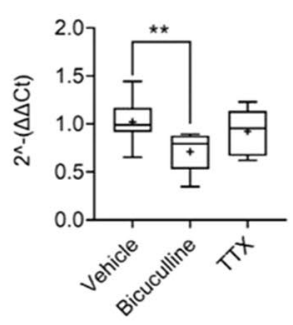

C

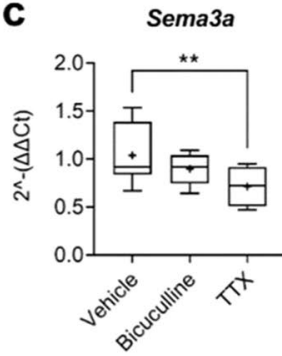

f

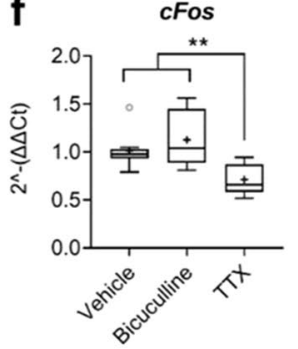

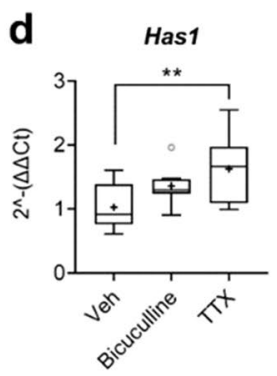

g

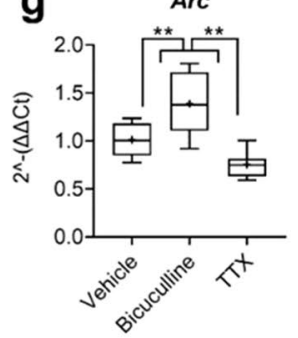

Fig. 2 Bicuculline increased IE gene expression and upregulated expression of Acan. Primary cortical neuronal cultures were treated with vehicle, bicuculline $(50 \mu \mathrm{M})$ or TTX $(2 \mu \mathrm{M})$ at 20 DIV for $16 \mathrm{~h}$. RNA was isolated at 21 DIV, cDNA synthesised and gene expression analysed via RT-qPCR. Heatmap of mean expression of normalised mRNA expression of key PNN-related, GABAergic and IE genes (a). Only genes showing a statistically significant change in expression are further presented as boxplots. Analysis revealed a substantial increase in Acan expression after bicuculline (main effect of treatment, $F_{2,21}=52.59, p<0.000$; Tukey, vehicle vs. bicuculline: $p<0.01)(\mathbf{b})$. Expression of all other CSPG genes were unaffected by bicuculline or TTX. In addition, TTX treatment significantly downregulated expression of Sema3a (main effect of treatment, $F_{2,21}=3.82, p=0.038$; Tukey, vehicle vs. TTX: $\left.p<0.01\right)$ (c) and upregulated Hasl (main effect of treatment, $F_{2,21}=4.35, p=0.026$; Tukey, vehicle vs. TTX: $p<0.01)(\mathbf{d})$. In terms of GABAergic gene expression, there were no significant differences in Pvalb, Sst, Gadl or Gad2 compared to vehicle, after either bicuculline or TTX. However, bicuculline downregulated Dlg4 (PSD-95) (e). Assessment of activity-dependent markers revealed elevated expression of IE genes, $c F o s$ and Arc, after bicuculline (main effect of treatment, $F_{2,21}=7.58, p=0.003$; Tukey, vehicle vs. bicuculline: $c$ Fos: $p<0.01$, Arc: $p<0.01)$. However, compared to vehicle, TTX reduced $c F o s$ expression (Tukey, vehicle vs. TTX: $p<0.01$ ). Arc was significantly lower in TTX vs. bicuculline conditions (Tukey, bicuculline vs. TTX: $p<0.01)(\mathbf{f}, \mathbf{g})$. Relative expression was calculated using $\Delta \Delta \mathrm{Ct}$ method with $T b p$ housekeeping gene. $N=8$ independent samples derived from 4 independent cultures per condition. Data are presented as boxplots with medians, interquartile ranges and 'Tukey' whiskers; crosses indicate sample means. Data were analysed via one-way ANOVA with Tukey post hoc multiple comparisons. ** represents Tukey post hoc significance compared to vehicle $(p<0.01)$ 
Interestingly, TTX treatment demonstrated no apparent effect on CSPG expression (Fig. 2a). However, TTX-treated cultures expressed significantly lower Sema3a (encoding the secreted chemorepulsive protein SEMA3A which binds to PNNs via interactions with chondroitin sulphate). A modest increase in Has 1 mRNA expression was also found (Fig. 2c, d).

\section{ChABC Treatment Decreases JNK Phosphorylation}

The role of JNK signalling in several developmental processes within the CNS has become apparent [70-75]. Our previous work has highlighted JNK and other MAPK signalling molecules, including TAOK2 and ERK, as key players in the maturation of GABAergic interneurons [76]. More specifically, our work has revealed a modulatory role for JNK in the development and regulation of PNNs. However, as yet, the effects of PNN ablation on neuronal MAPK signalling remain unclear. Hence, we aimed to understand the consequences of enzymatic PNN digestion on two key MAPK signalling pathways, JNK and ERK.

Western blot quantification revealed a distinct reduction in all phosphorylated JNK (pJNK) isoforms (p48, p54 and p56) in cultured primary cortical interneurons treated with ChABC, compared to vehicle (Fig. 3a, b). Our data indicate no clear difference in levels of phosphorylated ERK (pERK) isoforms (p42 or p44) in cultured cortical neurons treated with ChABC, compared to vehicle (Fig. 3c, d).

Given the suggested role of PNNs in synaptic plasticity, we contrasted the above results of ChABC treatment on pJNK and pERK levels with the consequences of bicuculline and TTX administration on activity within these pathways. Western blots revealed an increase in pJNK p54 and p56 after bicuculline, compared to vehicle (Fig. 3e, f). There was also a non-significant, but suggestive, trend towards an increase in pJNK p48 following bicuculline treatment $(p=0.079)$. No tangible differences in pJNK expression were found in response to TTX treatment. Similarly, there were no significant differences in levels of pERK after TTX administration in cultured cortical neurons. However, bicuculline appeared to increase pERK (pERK p42, $p<0.05$; pERK p44, $p=0.06)$.

\section{ChABC-Induced PNN Degradation Induces an Immature Neuronal Phenotype In Vitro}

Our data indicate clear differences between the effects of ChABC and bicuculline/TTX treatment in cortical neuronal cultures. In particular, a number of markers which are related to synaptic plasticity, network activity and interneuron network dynamics (including Arc, Pvalb, Sst, Dlg4 expression, along with pJNK and pERK activity) are differentially regulated by these treatments. Moreover, our data indicate that
ChABC, bicuculline and TTX treatments produce divergent expression patterns of PNN components.

As previously discussed, the maturation of PNNs may act as so-called brakes on plasticity, with the maturation of these nets being linked with closure of the critical period and the associated state of 'juvenile' plasticity. Considering this, we sought to understand whether the observed phenotypic differences in ChABC versus bicuculline/TTX treatment indicated the initiation of a 'juvenile-like' phenotype by ChABC-induced PNN ablation, rather than a more classical modulation of plasticity within mature cortical neurons. Accordingly, we measured expression of four developmentally regulated genes (Ascll, Dlx2 and Pax6, transcription factors important in early cortical development, and Kcncl, a potassium channel subunit expressed later in development) in cultured primary cortical neurons treated with either vehicle, ChABC, bicuculline or TTX.

We found upregulated expression of both Ascll (otherwise known as MASH-1) and Dlx2 after ChABC PNN digestion, compared to vehicle (Fig. 4a, b). In addition, compared to vehicle, ChABC treatment downregulated expression of developmentally regulated Kcncl (Fig. 4c), a gene which encodes Kv3.1b potassium channels that are enriched in fast-spiking PVB interneurons [77, 78]. No difference in expression of the transcription factor Pax 6 was found in response to $\mathrm{ChABC}$ treatment.

RT-qPCR revealed no differences in Ascll, Dlx2 or Kcncl expression after either bicuculline or TTX treatment, compared to vehicle. However, a modest downregulation of Pax6 was found after bicuculline administration.

\section{ChABC Upregulated Taok2 Expression with No Effect on Bdnf mRNA Levels}

Adequate BDNF expression is crucial to the closure of the critical period of cortical plasticity [43-45]. Our data regarding expression of developmentally regulated genes (Fig. 5) indicated a potential induction of a 'juvenile'-like state of cultured cortical neurons which may be more akin to a 'reopening' of the critical period of cortical plasticity, rather than a heightened state of mature synaptic plasticity induced by bicuculline. With this in mind, we measured $B d n f$ expression in cultures treated with either vehicle, ChABC, bicuculline or TTX. In addition, given the clear impact of ChABCinduced PNN digestion on pJNK, we investigated whether expression of upstream kinase Taok2 might be altered in these cultures.

RT-qPCR analysis revealed no difference in $B d n f$ expression after ChABC treatment, compared to vehicle (Fig. 5a). Heightened levels of Taok2 mRNA were observed in neuronal cultures treated with ChABC (Fig. 5b). Conversely, we observed heightened $B d n f$ mRNA expression after bicuculline treatment (Fig. 5c), 


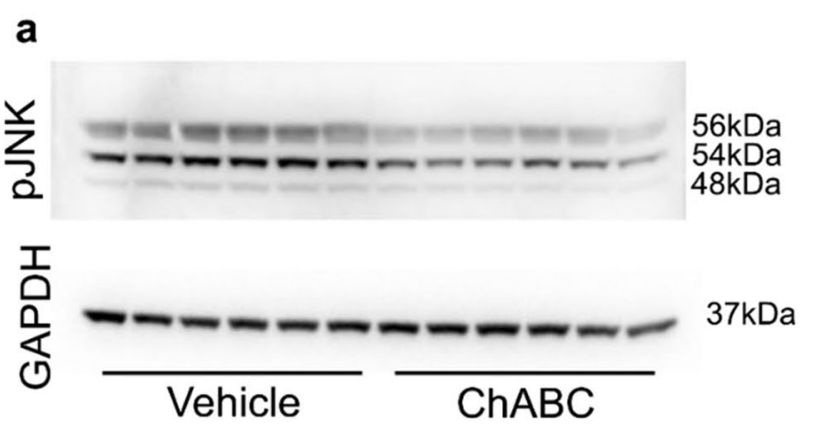

C
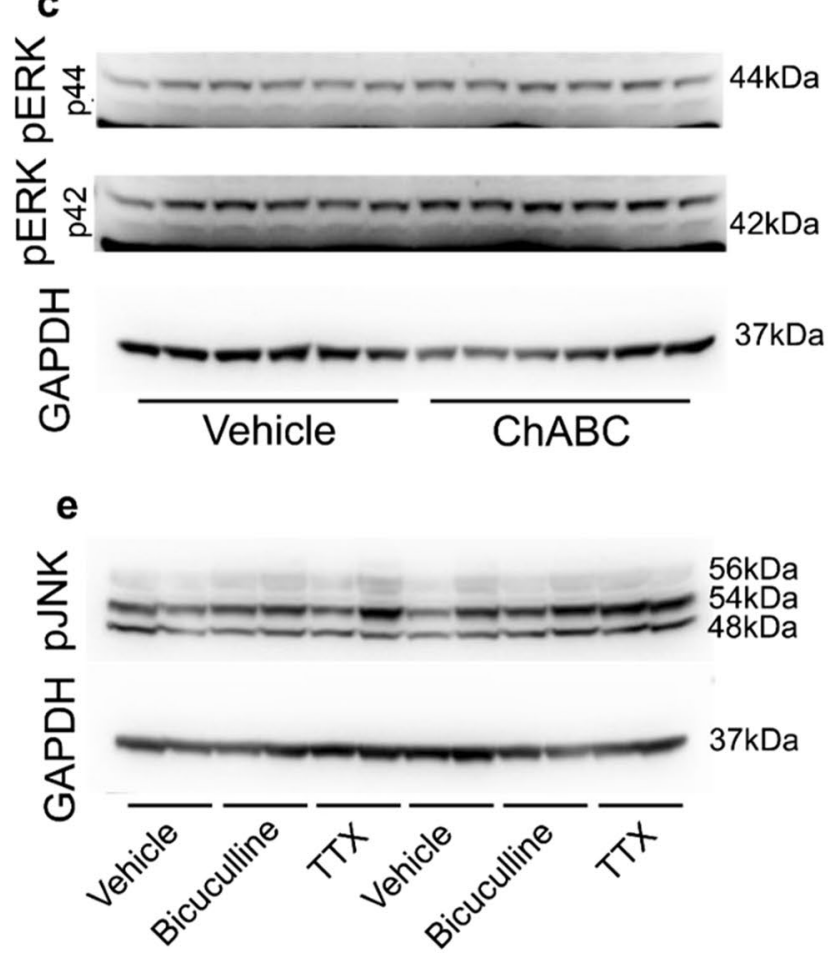

g

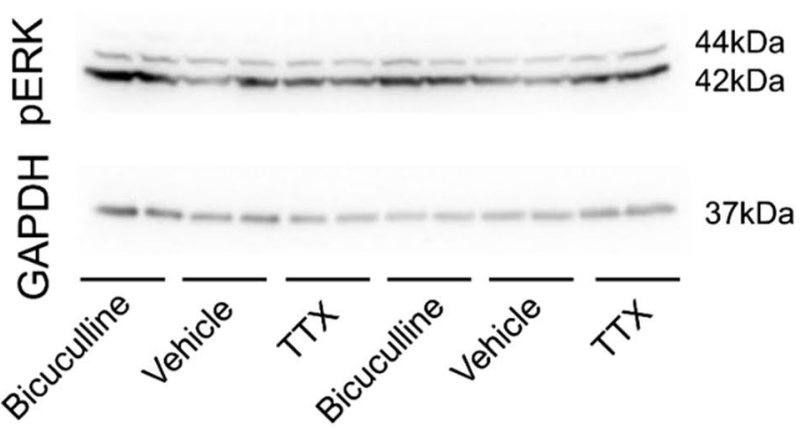

with no effect on Taok2 expression (Fig. 5d). TTX treatment downregulated $B d n f$ expression but, similarly to bicuculline, produced no change in Taok 2 mRNA levels (Fig. 5c, d). b
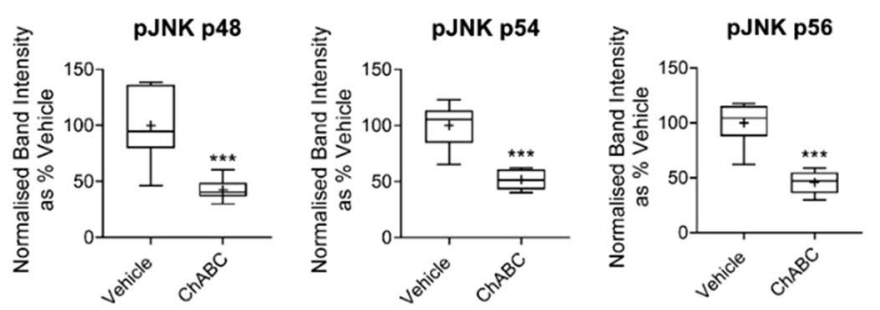

d
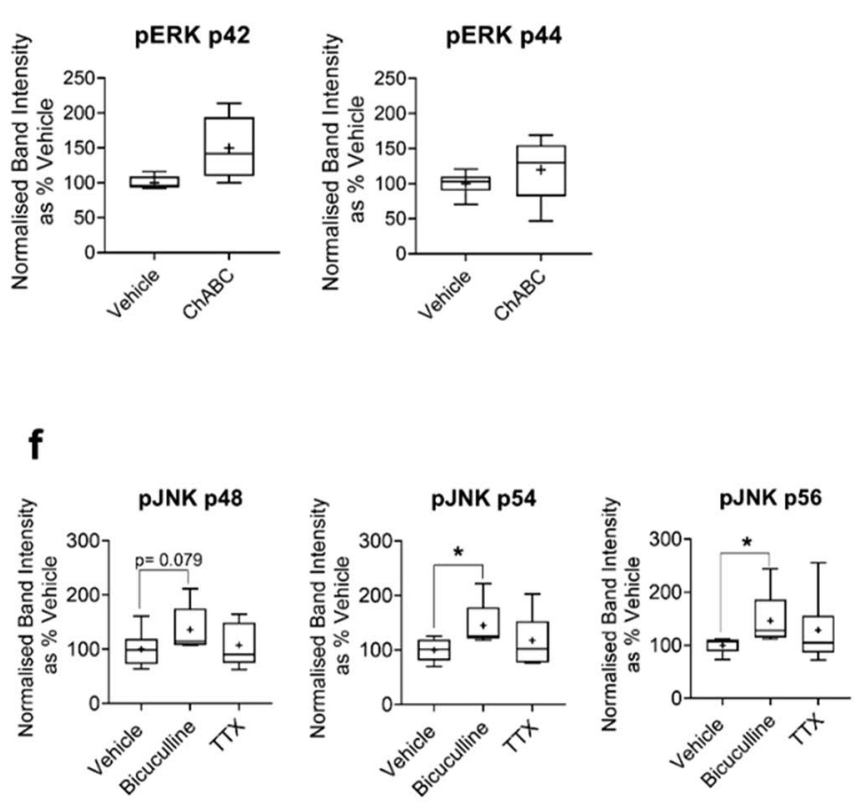

h

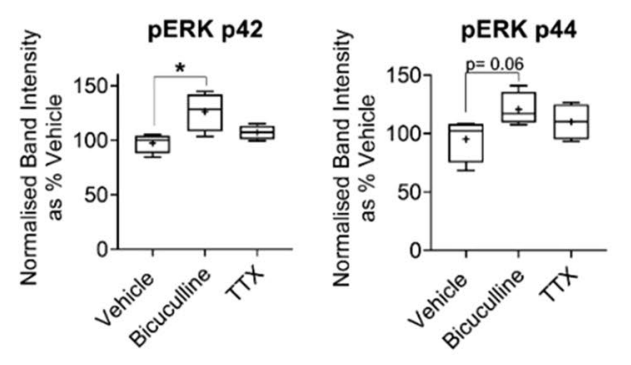

\section{BDNF Treatment Upregulated Expression of Key PNN Components, Increased Gad Expression and Elevated IE Gene Expression in a TAOK-Dependent Manner}

BDNF is another known modulator of synaptic transmission and plasticity which has potent effects at adult synapses. 
4Fig. $3 \mathrm{ChABC}$ and bicuculline differentially regulated MAPK signalling pathways. pJNK and pERK levels were assessed in protein extracts from primary cortical neuronal cultures via Western blots. Cultures were treated with either vehicle vs. ChABC $(30 \mathrm{mU} / \mathrm{ml}$; 18-21 DIV) (a-d; $N=6$ independent samples derived from 3 independent cultures per condition) or vehicle, bicuculline $(50 \mu \mathrm{M})$ or TTX $(2 \mu \mathrm{M})$ (20-21 DIV, 16-h stimulation) (e-h; $N=8$ independent samples derived from 4 independent cultures per condition). ChABC degradation of PNNs substantially reduced levels of all pJNK isoforms $(p<0.001)(\mathbf{a}, \mathbf{b})$. pERK levels $(\mathbf{c}, \mathbf{d})$ were not significantly changed by $\mathrm{ChABC}$ treatment. Bicuculline upregulated levels of pJNK p54 and p56 isoforms $(p<0.05)$ and data suggested a possible trend towards bicuculline upregulation of pJNK p48 $(p=0.079)$. Bicuculline increased pERK p42 $(p<0.05)$, with a trend towards increased pERK p44 $(p=0.06)$. TTX treatment did not significantly alter pJNK or pERK levels $(\mathbf{e}, \mathbf{f})$. Band intensity was measured via ImageJ and normalised to GAPDH. Intensity values were then expressed as a percentage of vehicle. Data are presented as boxplots with medians, interquartile ranges and 'Tukey' whiskers; crosses indicate sample means. Data were analysed via one-way ANOVA with Tukey post hoc multiple comparisons, $* * *$ represents $p<0.001$ compared to vehicle

Our previous work has highlighted that BDNF treatment of immature primary cortical neuronal cultures accelerates cortical interneuron maturation, and in particular, increases PNN density in a JNK-dependent manner [76]. This work has also implicated TAOK2, an upstream activator of JNK, in the appropriate development of PVB + interneurons and PNNs.

Considering this, we investigated the effects of exogenous BDNF treatment from 14 to 21 DIV on PNN-related and GABAergic gene expression and aimed to elucidate whether any effects were reliant on TAOK. We measured PNN, GABAergic and IE gene expression in cultures treated with either vehicle, TAOK inhibitor (CP-43), BDNF or CP-43 + BDNF.

Our data revealed a clear BDNF-induced elevation of Ncan, Sema3a, Gad1, Gad2, cFos and Arc (Fig. 6a-c, f-i). In the case of Sema3a, cFos and Arc, this upregulation was attenuated when CP-43 and BDNF were administered concomitantly. An observable reduction in Ncan, Gadl and Gad 2 expression was present in BDNF + CP-43 conditions, compared to BDNF-only, although the effects were not statistically significant.

TAOK inhibition via CP-43 upregulated Has 1 expression; this increase was not observed in CP-43 + BDNF conditions (Fig. 6d). A modest, although non-significant, elevation in Has3 expression was also found after CP-43 treatment (Fig. 6e). Again, this heightened expression was attenuated when BDNF was administered alongside CP-43 (Fig. 6).

\section{Discussion}

Our work aimed to understand the molecular consequences of ChABC digestion of PNNs, with a specific focus on expression of PNN-related, GABAergic and IE genes, and
MAPK signalling. MAPK signalling downstream of BDNF has been linked with GABAergic interneuron maturation. Hence, we investigated the effects of ChABC treatment on key MAPK signalling pathways, JNK and ERK. We contrasted ChABC-induced changes with those observed after the application of well-known modulators of mature synaptic plasticity and network activity in cortical neurons, bicuculline and TTX. PNN digestion resulted in an immature molecular phenotype as evidenced by an upregulation of Has2, Ascll and Dlx2 together with downregulation of Kcncl and Bcan. PNN ablation also downregulated JNK activity. Conversely, bicuculline and TTX did not induce a phenotype typical of immaturity, and bicuculline upregulated phosphorylation of several JNK and ERK isoforms. Finally, in light of work demonstrating JNK-dependent effects of BDNF on the regulation of interneuron and PNN development, we examined the involvement of upstream kinase, TAOK, on BDNF modulation of PNN and plasticity-related genes. We found that BDNF modulation of IE genes and PNN component, Sema3a, was TAOK-signalling dependent.

\section{In Vitro ChABC Digestion of PNNs Induces an Immature Molecular Phenotype in Cortical Neurons}

Our data indicate the induction of an immature neuronal phenotype after enzymatic degradation of PNNs in vitro. Our initial experiments revealed that $\mathrm{ChABC}$ treatment of primary neuronal cultures downregulated Bcan expression, while it upregulated Has 2 mRNA levels. Previous work has highlighted a tight developmental regulation of these genes. Bcan expression is lowest during embryonic development and maximal in the mature brain, with upregulation becoming particularly prominent around the closure of the critical period of cortical plasticity [79]. Conversely, in vitro Has 2 expression is highest between 3 and 14 DIV, after which expression decreases to almost non-detectable levels at 21 DIV [69].

These primary indications of an immature neuronal phenotype after $\mathrm{ChABC}$ treatment were strengthened by assessment of well-characterised developmentally regulated genes, Ascll, Dlx2 and Kcncl. We found upregulated expression of both Ascll (otherwise known as MASH-1) and Dlx2 after ChABC PNN digestion. Ascll is best known for its role in neurogenesis and as a neuronal progenitor marker [80, 81]. Transcription factor, $D l x 2$, guides a number of developmental programmes which are critical to GABAergic development, including tangential interneuron migration to the neocortex and interneuron differentiation [82-84]. Both Ascl1 and $D l \times 2$ are highly expressed during early developmental stages, with their expression diminishing to extremely low levels between postnatal day 10 and 15 [85]. In addition, ChABC treatment downregulated expression of Kcncl, a 

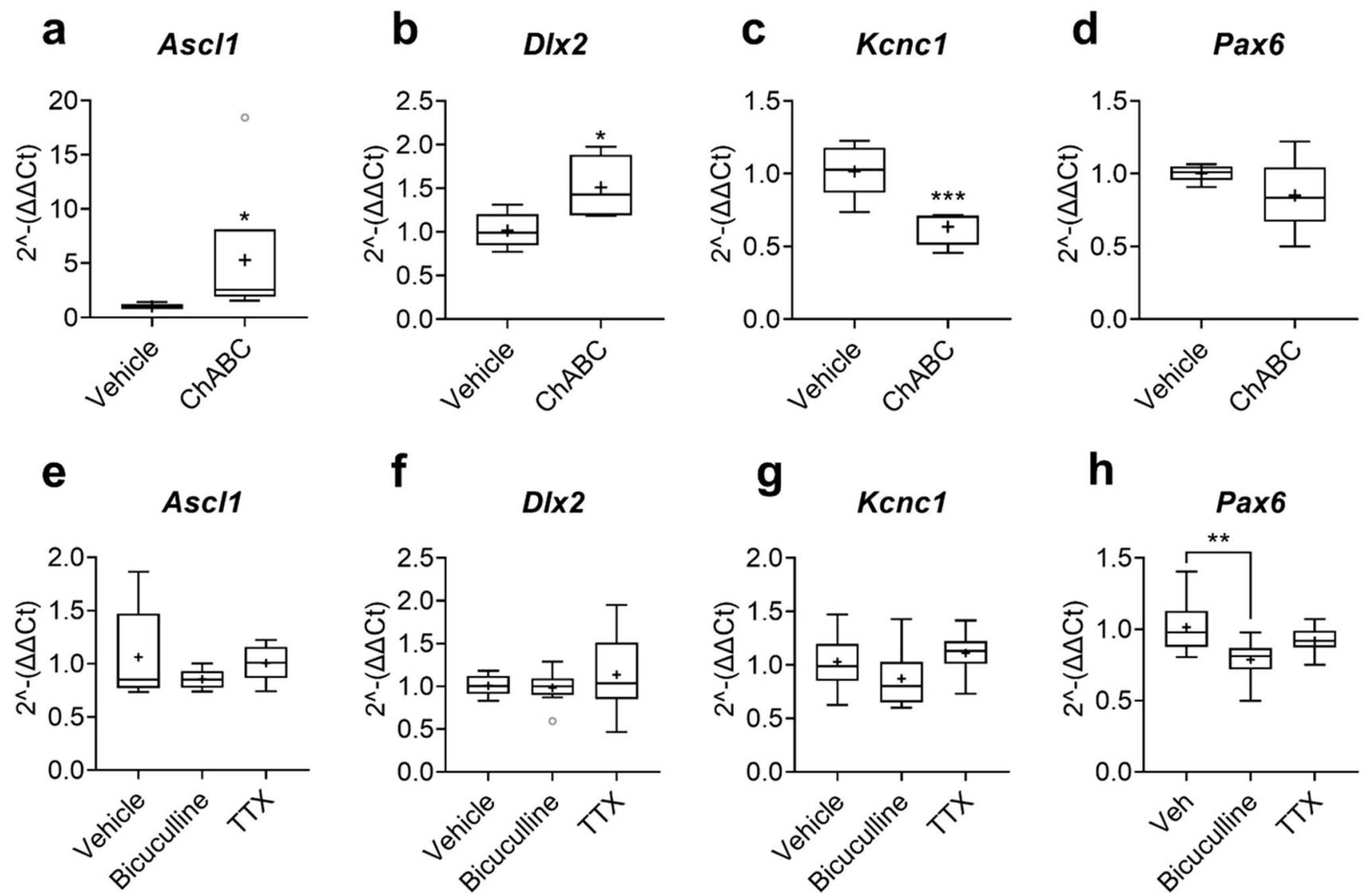

Fig. 4 ChABC treatment produced a pattern of gene expression indicative of immature interneurons. Expression of developmentally regulated genes, Ascll, Dlx2, Kcncl and Pax6, were assessed in primary cortical neuronal cultures treated with either vehicle or ChABC (30 mU/ml) from 18 to 21 DIV (a-d) or vehicle, bicuculline $(50 \mu \mathrm{M})$ or TTX $(2 \mu \mathrm{M})$ from 20 to 21 DIV (16-h stimulation) (e-h) via RTqPCR. The expression of these genes was interpreted as a measurement of relative maturity of neuronal cultures, with Dlx2 and Kcncl predominantly reflecting interneuron maturity status. We found substantial increases in Dlx2 $(p=0.012)$ and Ascl1 (MASH1) $(p=0.050)$, along with a significant decrease in Kcncl expression $(p=0.001)$, after ChABC treatment. No differences were observed in Dlx2, Ascll

gene which encodes Kv3.1b voltage-gated potassium channels that are enriched in fast-spiking PVB + interneurons $[77,78]$. Kcncl expression is almost undetectable throughout early development, with expression steadily increasing to maximal levels in the mature brain [85]. Previous work has shown that BCAN forms protein complexes with both Kv1.1 and $\mathrm{Kv} 3.1 \mathrm{~b}$ and has shown that Bcan knockdown reduces Kv3.1b density on PVB + interneurons (likely, of the basket cell subtype) [86]. The relationship between voltage-gated potassium channel Kv3.1b and BCAN adds further interest to our finding that both $\mathrm{Bcan}$ and $\mathrm{Kcncl}$ are downregulated after PNN digestion.

No difference in expression of the transcription factor Pax6 was detected in response to ChABC treatment. Pax6 expression is tightly linked to glutamatergic cell

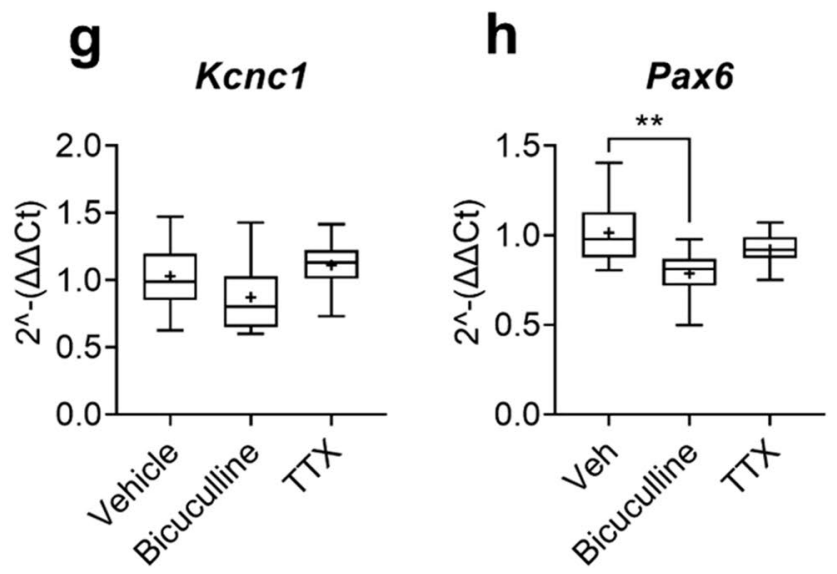

or Kcncl expression after bicuculline or TTX stimulation. Bicuculline treatment decreased Pax6 expression (main effect of treatment, $F_{2,21}=4.71, p=0.020$; Tukey, vehicle vs. bicuculline: $p<0.01$ ), whereas no significant difference was found in Pax6 expression after ChABC treatment. Relative expression was calculated using $\Delta \Delta \mathrm{Ct}$ method with Gapdh housekeeping gene. $N=8$ independent samples derived from 4 independent cultures per condition. Data are presented as boxplots with medians, interquartile ranges and 'Tukey' whiskers; crosses indicate sample means. Data were analysed via one-way ANOVA with Tukey post hoc multiple comparisons. *,** and *** represent Tukey post hoc significance compared to vehicle $(p<0.05$, $p<0.01$ and $p<0.001$, respectively)

differentiation, with maximal expression during embryonic and early postnatal development $[87,88]$. After this period, expression of Pax6 rapidly declines and is detectable only in immature neurons of the olfactory bulb and dentate gyrus where it may be associated with adult neurogenesis [89].

We suggest that this clear dysregulation of Bcan, Has2, $D l x 2$ and $K c n c 1$, coupled with no alteration to glutamatergic associated Pax6, may illustrate an immature phenotype elicited by ChABC. This may specifically affect cortical interneurons. Indeed, this suggestion is in line with previous reports which appear to show predominant effects of ChABC on inhibitory interneuron physiology, with no impact on intrinsic excitatory cell properties $[22,90]$. However, PNN constituents can also be found at synapses on excitatory neurons [91], and the changes in Arc observed 

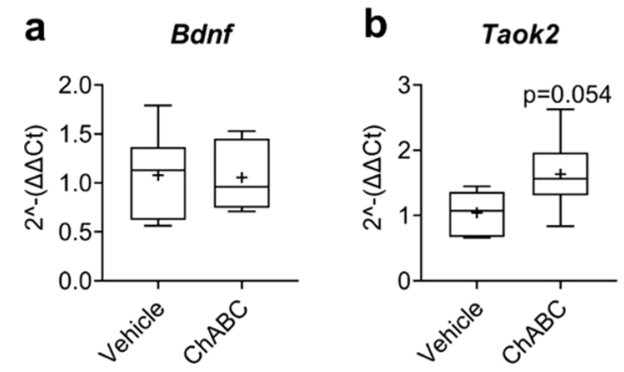

Fig. 5 Taok2 expression was elevated after ChABC with no effect on Bdnf expression, while both bicuculline and TTX modulated $B d n f$ expression with no significant consequence to Taok2 expression. Expression of $B d n f$ and Taok2 were measured via RT-qPCR in cultures treated with either $(\mathbf{a}, \mathbf{b})$ vehicle or ChABC $(30 \mathrm{mU} / \mathrm{ml})$ from 18 to $21 \mathrm{DIV}$, or $(\mathbf{c}, \mathbf{d})$ vehicle, bicuculline $(50 \mu \mathrm{M})$ or TTX $(2 \mu \mathrm{M})$ from 20 to 21 DIV (16-h stimulation). ChABC treatment had no effect on $B d n f$ expression, whereas bicuculline upregulated and TTX downregulated $B d n f$ (main effect of treatment, $F_{2,21}=28.25$, $p<0.000$; Tukey vehicle vs. bicuculline: $p<0.001$, vehicle vs. TTX:

are likely to reflect changes in activity of principal cells, so this hypothesis requires further investigation.

\section{Upregulation of Pvalb Expression Contrasts with Reversion to Immature Phenotype}

We found an upregulation of Pvalb following ChABC digestion of PNNs. Previous work has demonstrated that induction of Pvalb mRNA expression correlates with the functional maturation of cortical interneurons [92, 93]. In fact, there is evidence that PVB interneuron maturation is responsible for critical period closure [27, 94]. This finding may appear counterintuitive to our data which suggest an immature interneuron phenotype in vitro. However, some previous work has highlighted that attenuation of PNNs via ChABC selectively increases the excitability of fast-spiking (FS) PVB interneurons [22], although there are conflicting reports [20]. Nonetheless, given that $P v a l b$ expression appears to be activity dependent [95-97], an elevation in Pvalb expression after ChABC could be in line with previous observations of heightened PVB cell excitability following $\mathrm{ChABC}$ treatment in vitro.

Our findings of increased Pvalb and Ascll mimic reports from tenascin-R deficient mice, in which PVB cell number and Ascll expression are increased [98]. Tenascin- $\mathrm{R}$ is an extracellular link protein which contributes to the assembly and stabilisation of PNNs, and mice lacking tenascin-R have severely compromised PNNs [99]. Hence, it is interesting that the chronic impairment of PNNs in these animals produces a somewhat similar result to the data we report from ChABC PNN digestion in vitro.

The data presented in the current work are insufficient to provide conclusive evidence regarding the functional
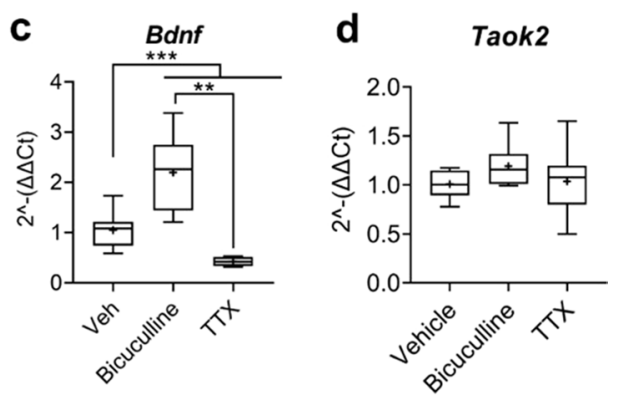

$p<0.001$, bicuculline vs. TTX: $p<0.01)$. Conversely, ChABC increased Taok2 expression $(p=0.054)$, while both bicuculline and TTX had no effect. Relative expression was calculated using $\Delta \Delta \mathrm{Ct}$ method with Gapdh housekeeping gene. $N=8$ independent samples derived from 4 independent cultures per condition. Data are presented as boxplots with medians, interquartile ranges and 'Tukey' whiskers; crosses indicate sample means. Data were analysed via one-way ANOVA with Tukey post hoc multiple comparisons. ** and *** represent Tukey post hoc significance compared to vehicle $(p<0.01$ and $p<0.001$, respectively)

consequence of a ChABC-induced immature molecular phenotype on PVB interneuron spiking activity or wider functional consequences to the inhibitory interneuron network. However, they do demonstrate regulation of mRNAs related to key subclasses of cortical GABAergic interneurons: ChABC digestion of PNNs upregulated Pvalb and downregulated Sst expression. Together, Pvalb and Sst interneuron subclasses form a major control mechanism which set cortical excitatory-inhibitory balance [100-102]. PVB interneurons exert strong inhibition onto pyramidal cells, but also inhibit other PVB interneurons. In addition, SST interneurons inhibit all other interneuron subclasses, but not one another [103]. ChABC-induced changes to these markers could indicate changes to inhibitory network dynamics following PNN degradation.

Our data which demonstrate a ChABC-induced reduction of Kcncl, indicating a loss of Kv3.1b channels, which endow PVB interneurons with their FS ability [104-107], may support the notion of altered electrophysiological characteristics of interneurons following PNN removal. Future work would be well placed to investigate the functional consequences of a ChABC-induced immature molecular phenotype. This work may provide a richer understanding of the cellular phenotype underpinning the apparent juvenile-like plasticity which has previously been reported by in vivo ChABC studies [24, 37].

It is important to note that no significant change in Gad1 expression was found in ChABC-treated cultures (Fig. 1a). However, it is possible that the opposing regulation of two distinct interneuron subclasses of interneurons, $P$ valb and Sst, after ChABC treatment may result in no net change in GAD67 GABA synthesis. 

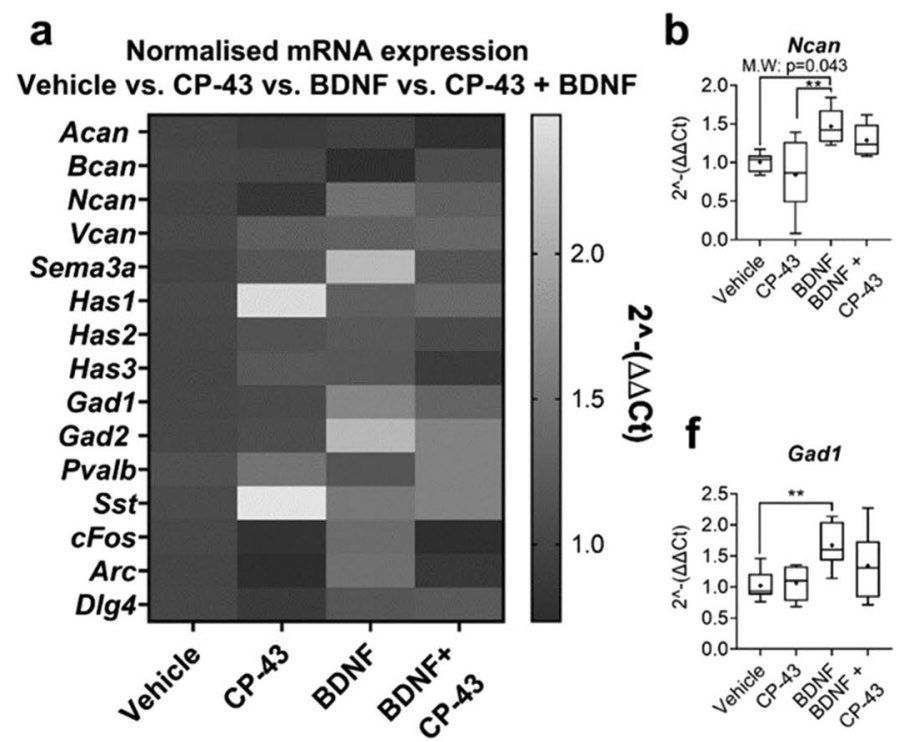
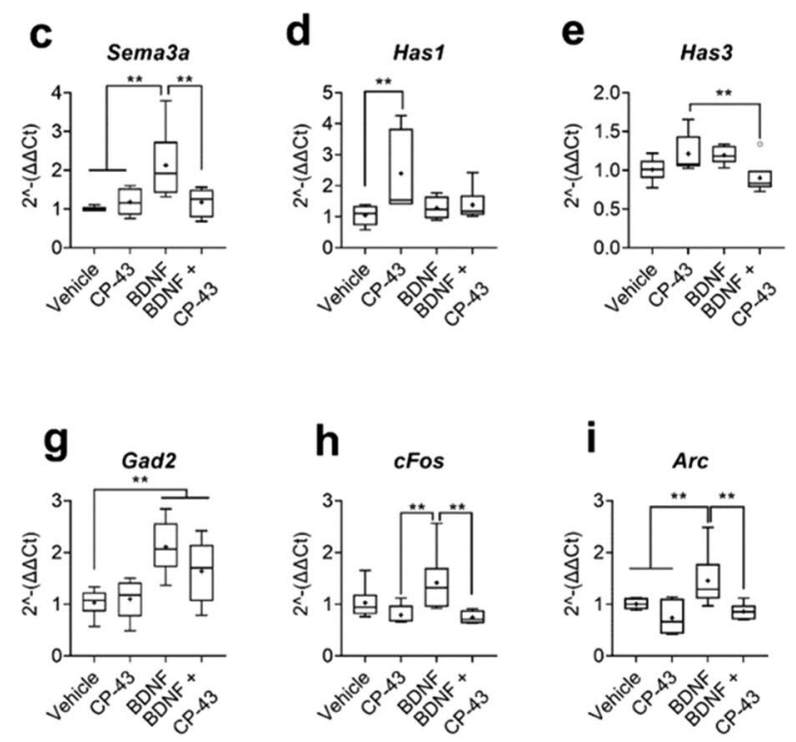

Fig. 6 BDNF treatment upregulated expression of key PNN components, increased $\mathrm{Gad} 1 / \mathrm{Gad} 2$ and elevated IE gene expression in a TAOK-dependent manner. Primary cortical neuronal cultures were treated with either vehicle, TAOK inhibitor $(\mathrm{CP}-43 ; 30 \mu \mathrm{M})$, BDNF $(50 \mathrm{ng} / \mathrm{ml})$ or $\mathrm{CP}-43+\mathrm{BDNF}$ from 14 to $21 \mathrm{DIV}$. Expression of key PNN-related, GABAergic and IE genes were measured via RTqPCR. Heatmap of mean expression of normalised mRNA expression of key PNN-related, GABAergic and immediate-early genes (a). Only genes showing a statistically significant change in expression are further presented as boxplots. We found that BDNF significantly increased Ncan (Mann-Whitney: CI (0.0380, 0.7895), $p=0.043$ ) (b) and Sema3a (main effect of treatment, $F_{3,19}=5.60, p=0.006$; Tukey, vehicle vs. BDNF: $p<0.01)(\mathbf{c})$; this effect was attenuated by TAOK inhibition (Tukey, BDNF vs. CP-43+BDNF: $p<0.01$ ). TAOK inhibition alone significantly upregulated expression of Hasl (main effect of treatment, $F_{3,19}=3.63, p=0.032$; Tukey, vehicle vs. CP-43: $p<0.01$ ) and there was a non-significant trend towards CP-43 increasing Has 3 expression (d, e). These CP-43-dependent elevations appear to be attenuated with the application of exogenous BDNF (i.e. $\mathrm{CP}-43$ vs. BDNF + CP-43; Has3: Tukey, CP-43 vs. BDNF $+\mathrm{CP}-43$,

\section{ChABC-Induced Juvenile-Like States Are Unlike Classically Induced Homeostatic Plasticity by Bicuculline and TTX}

In vivo PNN disruption can induce juvenile ocular dominance plasticity in the mature brain [24] and shift the neural network into an immature state [108]. There are also indications that PNNs are involved in AMPA receptor mobility and may modulate short-term synaptic plasticity in vitro [109]. Importantly, while mature PNNs contribute to an extracellular state which restricts synaptic plasticity, these structures also have a crucial role in synaptic stabilisation [110]. Hence, reduced PNN density throughout development may enable anatomical states in which heightened synaptic flexibility and sprouting is permitted [1], whereas the structural 'tightening' of these nets in the mature brain performs a crucial role in both $p<0.01$ ). BDNF upregulated expression of Gadl (main effect of treatment, $F_{3,19}=3.56, p=0.034$; Tukey, vehicle vs. BDNF: $p<0.01$ ) and Gad2 (main effect of treatment, $F_{3,19}=7.29, p=0.002$; Tukey, vehicle vs. BDNF: $p<0.01)(\mathbf{f}, \mathbf{g})$. There was a non-significant trend towards TAOK inhibition attenuating this effect. BDNF treatment also elevated expression of IE genes, cFos (main effect of treatment, $F_{3,19}=4.13, p=0.021$; Tukey, vehicle vs. BDNF: $p<0.01$ ) and $\operatorname{Arc}$ (main effect of treatment, $F_{3,19}=4.05, p=0.022$; Tukey, vehicle vs. BDNF: $p<0.01)(\mathbf{h}, \mathbf{i})$. Again, this elevation was negated when TAOK was inhibited (Tukey, BDNF vs. BDNF+CP-43: cFos: $p<0.01$, Arc: $p<0.01)$. Relative expression was calculated using $\Delta \Delta \mathrm{Ct}$ method with Gapdh housekeeping gene. $N=8$ independent samples derived from 4 independent cultures per condition. Data are presented as boxplots with medians, interquartile ranges and 'Tukey' whiskers; crosses indicate sample means. Data were analysed via two-way ANOVA with Tukey post hoc multiple comparisons. Factors BDNF and inhibitor, with BDNF and inhibitor crossed to investigate any potential interaction. $* *$ represents Tukey post hoc significance compared to indicate condition $(p<0.01)$. In addition, a Mann-Whitney $U$ test was performed for vehicle vs. BDNF on Ncan data

synaptic stabilisation and facilitation of the FS mode of PVB interneurons.

Our aforementioned data suggest that $\mathrm{ChABC}$ returns cortical neuronal cultures to a juvenile-like state, in which plasticity may be elevated, but where PVB interneuron FS activity may be impaired. We contrasted these results with well-known modulators of mature synaptic plasticity and network activity, bicuculline and TTX.

Primary cortical cultures are composed mainly of glutamatergic cells, with a smaller proportion of GABA interneurons [111]. Arc is localised to glutamatergic cells, but cFos can be induced in all cell types. While the cell type expressing these markers is not always clear, they do serve as highly informative markers of the state of network activity and resulting plasticity in the cultures. Our data highlight key phenotypic differences in the plasticity induced by bicuculline compared to that of ChABC. Similar 
to $\mathrm{ChABC}$ treatment, bicuculline upregulated expression of $c F o s$, an indication of heightened network activity [112]. However, our data also show a distinct upregulation of Arc following bicuculline administration which was not present in ChABC-treated cultures. The lack of Arc upregulation after $\mathrm{ChABC}$ is intriguing given the role of $A r c$ in synapsespecific homeostatic plasticity in glutamatergic cells [113], and may indicate that the same synapse-specific homeostatic scaling is not present, or as prominent, in juvenile-like states. Importantly, we found that TTX, a sodium channel blocker, substantially reduced $c F o s$ compared to vehicle. Expression of Arc was also significantly lower in TTX versus bicuculline-treated cultures. In addition, in line with previous findings [54], we found a reduction to $\mathrm{Dlg} 4$ (encoding PSD-95) expression following bicuculline treatment.

Neither bicuculline nor TTX push primary neuronal cultures back to a juvenile state; expression of developmentally regulated genes, Ascll, Dlx2 and Kcncl, was unchanged by either treatment. However, interestingly, we found a downregulation of Pax6 following bicuculline treatment. Pax6 is closely associated with the development of glutamatergic cells, but also plays a role in the mature CNS as a regulator of neurogenesis [114]. Since $\mathrm{GABA}_{\mathrm{A}^{-}} \mathrm{R}$ stimulation promotes neurogenesis [115], we interpret the downregulation of Pax6 by bicuculline as potentially linked to this aspect of $\mathrm{GABA}_{\mathrm{A}}-\mathrm{R}$ function.

In addition, we found a substantial upregulation in Acan expression following bicuculline, which fits with reports that suggest ACAN is a key activity-dependent component of PNNs [116, 117]. The precise contribution of individual CSPGs to PNN function is not currently known. However, Acan appears to be critical in formation of classically recognised mature PNNs, with Acan knockout mice exhibiting no WFA labelling [35]. Acan knockout in the mouse visual cortex apparently reinstates juvenile, but not mature, ocular dominance plasticity [27]. We suggest that the upregulation of Acan after bicuculline may indicate increased ACAN abundance within PNNs, potentially in response to elevated network activity. Consequently, unlike ChABC which appears to induce a more structurally permissive state, this may lead to denser PNNs which promote synaptic stabilisation and confer a more restrictive structural state. However, it should be noted that no reciprocal reduction in Acan expression was found in response to TTX-induced network activity reduction.

TTX downregulated expression of Sema3a and Hasl. These components were not significantly affected by bicuculline, which may suggest that the regulation of these does not relate solely to network activity, although further research is required.

Taken together, our data support the idea that ChABCinduced juvenile plasticity enables structural flexibility (as has been observed in the spinal cord $[118,119]$ and in
ChABC targeted axons [37]) and increases network disinhibition primarily via dysregulation of PVB interneuron FS activity. However, we suggest that $\mathrm{ChABC}$-induced plasticity is not akin to bicuculline-regulated mature plasticity, in which we see indications of heightened homeostatic plasticity and, potentially, a bolstering of synaptic stability.

\section{Juvenile-Like States May Be Related to Alterations in JNK Signalling}

Previous evidence has linked the JNK signalling pathway, along with upstream kinases, to key processes in GABAergic interneuron development [72-74, 120] including the regulation of various PNN components throughout development [76]. Moreover, members of the JNK family have been linked to synaptic plasticity [70, 121-125]. Considering this, we investigated the consequences of PNN removal in cortical neuronal cultures on JNK activity, and contrasted this with results from bicuculline and TTX treatment.

We found substantially lower levels of all pJNK isoforms following ChABC treatments. Our previous work has indicated that higher levels of JNK activity, along with upstream kinase TAOK2, are linked to an accelerated developmental phenotype in which PNN density is heightened prematurely [76]. Overall, our data support a role for JNK in ChABC effects. ChABC exposure reduced JNK activity. In previous work [76], we observed that direct inhibition of JNK downregulated Bcan and upregulated Has 2 expression-showing very good correspondence to the effects of ChABC. It is interesting that ablation of the PNN itself appears to have a consequence for JNK activity. This suggests a cross-regulation between these two developmentally important players. It is conceivable that if $\mathrm{ChABC}$ produces reversion to an immature neuronal state which recapitulates critical period like plasticity, an inherent reduction in JNK activity would be required for this phenotype. PNNs are known to reform in vivo a few weeks after ChABC treatment [25]. Future work may use longer-term timepoint studies of ChABC to better understand the reformation process in vitro. We hypothesise that there may be a coincidence of PNN reformation (e.g. heightened CSPG expression, return of WFA labelling), neuronal maturity and elevated TAOK2/JNK activity. Our experiments measuring Taok 2 expression may provide some support for this hypothesis; Taok2 expression was heightened following 3 DIV ChABC treatment. Given that Taok2 is an upstream activator of JNK, this upregulation may be the first sign of a move towards heightened TAOK2JNK signalling which could contribute to a restoration of PNNs and PVB interneuron maturity.

pJNK levels represent another key difference between ChABC- and bicuculline-induced plasticity states. TTX did not alter levels of pJNK or pERK isoforms. However, bicuculline increased levels of pJNK (particularly, p56 and p54) 
and pERK (particularly, p42). However, we found no change to the expression of upstream kinase Taok 2 in response to either bicuculline or TTX. We propose this may indicate that the downregulation of pJNK by ChABC owes to the induction of an immature neuronal phenotype, rather than a consequence of or response to increased network activity or plasticity.

The fact that pERK was not downregulated after ChABC fits with the idea that PNN maturation and regulation may interact specifically with the JNK signalling pathway. Indeed, our previous investigation revealed that inhibition of ERK has little effect on the expression of PNN components, with the exception of Sema3a [76]. Hence, it is perhaps unsurprising that there is no dysregulation of ERK activity downstream of PNN disruption.

\section{BDNF Modulates IE Gene Expression in a TAOK-Dependent Manner}

BDNF is a crucial player in cortical and hippocampal GABAergic interneuron maturation $[59,107,126,127]$ and has a regulatory role in the closure of the critical period of cortical plasticity and PNN maturation [43-45, 76].

Our data indicated no change in Bdnf expression following $\mathrm{ChABC}$ treatment. However, as may be expected in a heightened state of synaptic plasticity, $B d n f$ expression was significantly elevated after bicuculline treatment. This result is also in line with other reports which have found that in vivo $\mathrm{GABA}_{\mathrm{A}}-\mathrm{R}$ blockade increases cortical and hippocampal BDNF protein levels [128, 129].

BDNF itself is a known modulator of synaptic plasticity. Given that our previous work has revealed many of the accelerating effects of BDNF on interneuron and PNN development are reliant on JNK, we asked whether BDNF modulation of plasticity and interneuron/PNN regulation may also rely on upstream TAOK. To this end, we treated cultures with vehicle, BDNF, TAOK inhibitor (CP-43) or $\mathrm{BDNF}+\mathrm{CP}-43$, and measured expression of key PNN, GABAergic and IE genes.

At the treatment time and developmental stage studied, no significant effects of TAOK2 inhibition were detected on Bcan or Has 2 expression (Fig. 6) despite the clear downregulatory and upregulatory effects (respectively) of ChABC (Fig. 1), along with reduced JNK activity (Fig. 3). There are around 20 Map3Ks involved in JNK activation. TAOK2 is only one of these, so identical effects of inhibiting TAOK2 and JNK are not expected. In fact, the overlap between the effects of inhibition of TAOK2 and the effects of ChABC is quite limited, whereas the upregulation of TAOK2 by ChABC may imply a role for TAOK 2 more in a compensatory response to the induced immaturity.

We found a prominent upregulation of Ncan, Sema3a, Gad1, Gad2, cFos and Arc following BDNF treatment.
Interestingly, BDNF effects on Sema3a, cFos and Arc appear to be TAOK reliant, as the upregulation of these genes was negated when $\mathrm{CP}-43$ was administered concomitantly with BDNF. We suggest this indicates that BDNF induces a state of heightened synaptic plasticity and network activity in cortical neuronal cultures, which may be dependent on TAOK signalling. In addition, the observed upregulation of Gadl by BDNF treatment mirrors our previous data which show an elevation of GAD67 protein following exogenous BDNF treatment in cortical neuronal cultures [76].

SEMA3A supresses axonal growth while promoting dendritic branching and spine maturation [130, 131]. Moreover, NCAN has been shown to inhibit Sema3F-induced spine elimination [132] and promote neurite outgrowth [133]. The increase in both Ncan and Sema3a mRNA may relate to a heightened state of dendritic branching and suppression of axonal elaboration which is induced by BDNF and could, at least in part, rely on TAOK signalling.

Previous work has shown that TAOK2 knockdown in cultured neurons reduces neurite branching and increases growth cone collapse [134]. This group have reported similar abnormalities in Taok 2 heterozygous and knockout mice which demonstrate reductions in basal dendrite length, number of basal dendrite spines and dysregulation to spine morphology in these animals [135]. Hence, it is possible that disruption to TAOK2 signalling reduces responsiveness to BDNF-induced dendrite elaboration. This finding may hold clinical significance given the inclusion of Taok2 in the duplication and deletion of chromosome 16p11.2, copy number variants which have been highly associated with both schizophrenia and autism [136-138].

\section{Conclusions}

Overall, our data have revealed that PNN depletion induces an immature neuronal phenotype which is dissimilar from classically induced mature synaptic plasticity and may be related to JNK signalling. Our results suggest that PNN degradation may be linked with a more permissive environment which is conducive to heightened structural plasticity. The functional consequences of this immature molecular phenotype, and whether this impacts the phenotypic FS activity of PVB interneurons, require further investigation. We suggest that the observed immature molecular phenotype could underpin aspects of the induction of juvenile-like plasticity which has previously been observed following ChABC treatment in vivo. Finally, our work further underscores the importance of MAPK signalling downstream of BDNF in the modulatory effects of BDNF on plasticity.

Supplementary Information The online version contains supplementary material available at https://doi.org/10.1007/s12035-022-02772-z. 
Acknowledgements We would like to thank Mr John Craig for his excellent technical support throughout this project.

Author Contribution AW contributed to experimental design, conducted the experimental work and all the data analysis, and wrote the first draft of the manuscript. JAP and BJM conceived the project, contributed to experimental design and interpretation of the data, and helped draft the final version of the manuscript.

Funding We would like to thank the University of Glasgow, College of Medical Veterinary and Life Sciences Doctoral Training Programme for funding this work.

Availability of Data and Material Original data are available from the corresponding author on reasonable request.

\section{Declarations}

Consent for Publication All authors have consented to publication.

Competing Interests The authors declare no competing interests.

Open Access This article is licensed under a Creative Commons Attribution 4.0 International License, which permits use, sharing, adaptation, distribution and reproduction in any medium or format, as long as you give appropriate credit to the original author(s) and the source, provide a link to the Creative Commons licence, and indicate if changes were made. The images or other third party material in this article are included in the article's Creative Commons licence, unless indicated otherwise in a credit line to the material. If material is not included in the article's Creative Commons licence and your intended use is not permitted by statutory regulation or exceeds the permitted use, you will need to obtain permission directly from the copyright holder. To view a copy of this licence, visit http://creativecommons.org/licenses/by/4.0/.

\section{References}

1. Fawcett JW, Oohashi T, Pizzorusso T (2019) The roles of perineuronal nets and the perinodal extracellular matrix in neuronal function. Nat Rev Neurosci 20(8):451-465. https://doi.org/10. 1038/s41583-019-0196-3

2. Bekku Y, Rauch U, Ninomiya Y, Oohashi T (2009) Brevican distinctively assembles extracellular components at the large diameter nodes of Ranvier in the CNS. J Neurochem 108(5):12661276. https://doi.org/10.1111/j.1471-4159.2009.05873.x

3. Dours-Zimmermann MT, Maurer K, Rauch U, Stoffel W, Fässler R, Zimmermann DR (2009) Versican V2 assembles the extracellular matrix surrounding the nodes of ranvier in the CNS. The Journal of neuroscience : the official journal of the Society for Neuroscience 29(24):7731-7742. https://doi.org/10.1523/JNEUR OSCI.4158-08.2009

4. Celio MR, Spreafico R, De Biasi S, Vitellaro-Zuccarello L (1998) Perineuronal nets: past and present. Trends Neurosci 21(12):510515. https://doi.org/10.1016/s0166-2236(98)01298-3

5. Deepa SS, Carulli D, Galtrey C, Rhodes K, Fukuda J, Mikami T, Sugahara K, Fawcett JW (2006) Composition of perineuronal net extracellular matrix in rat brain: a different disaccharide composition for the net-associated proteoglycans. J Biol Chem 281(26):17789-17800. https://doi.org/10.1074/jbc.M600544200
6. Härtig W, Brauer K, Brückner G (1992) Wisteria floribunda agglutinin-labelled nets surround parvalbumin-containing neurons. NeuroReport 3(10):869-872. https://doi.org/10.1097/00001 756-199210000-00012

7. Berretta S, Pantazopoulos H, Markota M, Brown C, Batzianouli ET (2015) Losing the sugar coating: potential impact of perineuronal net abnormalities on interneurons in schizophrenia. Schizophr Res 167(1):18-27. https://doi.org/10.1016/j.schres. 2014.12.040

8. Wegner F, Härtig W, Bringmann A, Grosche J, Wohlfarth K, Zuschratter W, Brückner G (2003) Diffuse perineuronal nets and modified pyramidal cells immunoreactive for glutamate and the GABAA receptor $\alpha 1$ subunit form a unique entity in rat cerebral cortex. Exp Neurol 184(2):705-714. https://doi.org/10.1016/ S0014-4886(03)00313-3

9. Yamada J, Jinno S (2017) Molecular heterogeneity of aggrecanbased perineuronal nets around five subclasses of parvalbuminexpressing neurons in the mouse hippocampus. J Comp Neurol 525(5):1234-1249. https://doi.org/10.1002/cne.24132

10. Matthews RT, Kelly GM, Zerillo CA, Gray G, Tiemeyer M, Hockfield S (2002) Aggrecan glycoforms contribute to the molecular heterogeneity of perineuronal nets. J Neurosci 22(17):7536-7547. https://doi.org/10.1523/jneurosci.22-1707536.2002

11. Kwok JC, Carulli D, Fawcett JW (2010) In vitro modeling of perineuronal nets: hyaluronan synthase and link protein are necessary for their formation and integrity. J Neurochem 114(5):14471459. https://doi.org/10.1111/j.1471-4159.2010.06878.x

12. Carulli D, Rhodes KE, Fawcett JW (2007) Upregulation of aggrecan, link protein 1, and hyaluronan synthases during formation of perineuronal nets in the rat cerebellum. J Comp Neurol 501(1):83-94. https://doi.org/10.1002/cne.21231

13. Koppe G, Bruckner G, Hartig W, Delpech B, Bigl V (1997) Characterization of proteoglycan-containing perineuronal nets by enzymatic treatments of rat brain sections. Histochem J 29(1):11-20. https://doi.org/10.1023/A:1026408716522

14. Bekku Y, Su WD, Hirakawa S, Fässler R, Ohtsuka A, Kang JS, Sanders J, Murakami T, Ninomiya Y, Oohashi T (2003) Molecular cloning of Bral2, a novel brain-specific link protein, and immunohistochemical colocalization with brevican in perineuronal nets. Mol Cell Neurosci 24(1):148-159. https://doi.org/10. 1016/s1044-7431(03)00133-7

15. Asher RA, Scheibe RJ, Keiser HD, Bignami A (1995) On the existence of a cartilage-like proteoglycan and link proteins in the central nervous system. Glia 13(4):294-308. https://doi.org/10. 1002/glia.440130406

16. Dick G, Tan CL, Alves JN, Ehlert EME, Miller GM, Hsieh-Wilson LC, Sugahara K, Oosterhof A, van Kuppevelt TH, Verhaagen J, Fawcett JW, Kwok JCF (2013) Semaphorin 3A binds to the perineuronal nets via chondroitin sulfate type $\mathrm{E}$ motifs in rodent brains. J Biol Chem 288(38):27384-27395. https://doi.org/10. 1074/jbc.M111.310029

17. Wang D, Fawcett $\mathbf{J}$ (2012) The perineuronal net and the control of CNS plasticity. Cell Tissue Res 349(1):147-160. https://doi. org/10.1007/s00441-012-1375-y

18. Nabel EM, Morishita H (2013) Regulating critical period plasticity: insight from the visual system to fear circuitry for therapeutic interventions. Front Psychiatry 4:146. https://doi.org/10.3389/ fpsyt.2013.00146

19. Sigal YM, Bae H, Bogart LJ, Hensch TK, Zhuang X (2019) Structural maturation of cortical perineuronal nets and their perforating synapses revealed by superresolution imaging. Proc Natl Acad Sci U S A 116(14):7071-7076. https://doi.org/10.1073/ pnas. 1817222116 
20. Balmer TS (2016) Perineuronal nets enhance the excitability of fast-spiking neurons. eNeuro 3 (4). doi:https://doi.org/10.1523/ eneuro.0112-16.2016

21. Tewari BP, Chaunsali L, Campbell SL, Patel DC, Goode AE, Sontheimer H (2018) Perineuronal nets decrease membrane capacitance of peritumoral fast spiking interneurons in a model of epilepsy. Nat Commun 9(1):4724. https://doi.org/10.1038/ s41467-018-07113-0

22. Dityatev A, Brückner G, Dityateva G, Grosche J, Kleene R, Schachner M (2007) Activity-dependent formation and functions of chondroitin sulfate-rich extracellular matrix of perineuronal nets. Dev Neurobiol 67(5):570-588. https://doi.org/10.1002/ dneu. 20361

23. Hockfield S, Kalb RG, Zaremba S, Fryer H (1990) Expression of neural proteoglycans correlates with the acquisition of mature neuronal properties in the mammalian brain. Cold Spring Harb Symp Quant Biol 55:505-514. https://doi.org/10.1101/sqb.1990. 055.01.049

24. Pizzorusso T, Medini P, Berardi N, Chierzi S, Fawcett JW, Maffei L (2002) Reactivation of ocular dominance plasticity in the adult visual cortex. Science 298(5596):1248-1251. https://doi.org/10. 1126/science. 1072699

25. Brückner G, Bringmann A, Härtig W, Köppe G, Delpech B, Brauer K (1998) Acute and long-lasting changes in extracellularmatrix chondroitin-sulphate proteoglycans induced by injection of chondroitinase $\mathrm{ABC}$ in the adult rat brain. Exp Brain Res 121(3):300-310. https://doi.org/10.1007/s002210050463

26. de Vivo L, Landi S, Panniello M, Baroncelli L, Chierzi S, Mariotti L, Spolidoro M, Pizzorusso T, Maffei L, Ratto GM (2013) Extracellular matrix inhibits structural and functional plasticity of dendritic spines in the adult visual cortex. Nat Commun 4:1484. https://doi.org/10.1038/ncomms2491

27. Rowlands D, Lensjø KK, Dinh T, Yang S, Andrews MR, Hafting T, Fyhn M, Fawcett JW, Dick G (2018) Aggrecan directs extracellular matrix-mediated neuronal plasticity. J Neurosci 38(47):10102-10113. https://doi.org/10.1523/jneurosci.112218.2018

28. Suttkus A, Rohn S, Weigel S, Glöckner P, Arendt T, Morawski $M$ (2014) Aggrecan, link protein and tenascin-R are essential components of the perineuronal net to protect neurons against iron-induced oxidative stress. Cell Death Dis 5(3):e1119-e1119. https://doi.org/10.1038/cddis.2014.25

29. Carulli D, Pizzorusso T, Kwok JCF, Putignano E, Poli A, Forostyak S, Andrews MR, Deepa SS, Glant TT, Fawcett JW (2010) Animals lacking link protein have attenuated perineuronal nets and persistent plasticity. Brain 133(8):2331-2347. https:// doi.org/10.1093/brain/awq145

30. Blosa M, Sonntag M, Jäger C, Weigel S, Seeger J, Frischknecht R, Seidenbecher CI, Matthews RT, Arendt T, Rübsamen R, Morawski M (2015) The extracellular matrix molecule brevican is an integral component of the machinery mediating fast synaptic transmission at the calyx of Held. J Physiol 593(19):43414360. https://doi.org/10.1113/JP270849

31. Brakebusch C, Seidenbecher CI, Asztely F, Rauch U, Matthies H, Meyer H, Krug M, Böckers TM, Zhou X, Kreutz MR, Montag D, Gundelfinger ED, Fässler R (2002) Brevican-deficient mice display impaired hippocampal CA1 long-term potentiation but show no obvious deficits in learning and memory. Mol Cell Biol 22(21):7417-7427. https://doi.org/10.1128/mcb.22.21.74177427.2002

32. Prabhakar V, Capila I, Bosques Carlos J, Pojasek K, Sasisekharan $\mathrm{R}$ (2005) Chondroitinase ABC I from Proteus vulgaris: cloning, recombinant expression and active site identification. Biochemical Journal 386(1):103-112. https://doi.org/10.1042/bj20041222

33. Yamagata T, Saito H, Habuchi O, Suzuki S (1968) Purification and properties of bacterial chondroitinases and chondrosulfatases. J Biol Chem 243(7):1523-1535. https://doi. org/10.1016/S0021-9258(18)93574-X

34. Muir E, De Winter F, Verhaagen J, Fawcett J (2019) Recent advances in the therapeutic uses of chondroitinase ABC. Exp Neurol 321:113032. https://doi.org/10.1016/j.expneurol.2019. 113032

35. Giamanco KA, Morawski M, Matthews RT (2010) Perineuronal net formation and structure in aggrecan knockout mice. Neuroscience 170(4):1314-1327. https://doi.org/10.1016/j.neuroscien ce.2010.08.032

36. Pizzorusso T, Medini P, Landi S, Baldini S, Berardi N, Maffei L (2006) Structural and functional recovery from early monocular deprivation in adult rats. Proc Natl Acad Sci USA 103(22):85178522. https://doi.org/10.1073/pnas.0602657103

37. Day P, Alves N, Daniell E, Dasgupta D, Ogborne R, Steeper A, Raza M, Ellis C, Fawcett J, Keynes R, Muir E (2020) Targeting chondroitinase $\mathrm{ABC}$ to axons enhances the ability of chondroitinase to promote neurite outgrowth and sprouting. PLoS ONE 15(1):e0221851. https://doi.org/10.1371/journal.pone.0221851

38. García-Alías G, Barkhuysen S, Buckle M, Fawcett JW (2009) Chondroitinase $\mathrm{ABC}$ treatment opens a window of opportunity for task-specific rehabilitation. Nat Neurosci 12(9):1145-1151. https://doi.org/10.1038/nn.2377

39. Romberg C, Yang S, Melani R, Andrews MR, Horner AE, Spillantini MG, Bussey TJ, Fawcett JW, Pizzorusso T, Saksida LM (2013) Depletion of perineuronal nets enhances recognition memory and long-term depression in the perirhinal cortex. J Neurosci 33(16):7057-7065. https://doi.org/10.1523/ jneurosci.6267-11.2013

40. Anderson MD, Paylor JW, Scott GA, Greba Q, Winship IR, Howland JG (2020) ChABC infusions into medial prefrontal cortex, but not posterior parietal cortex, improve the performance of rats tested on a novel, challenging delay in the touchscreen TUNL task. Learn Mem 27(6):222-235. https://doi.org/ 10.1101/lm.050245.119

41. Paylor JW, Wendlandt E, Freeman TS, Greba Q, Marks WN, Howland JG, Winship IR (2018) Impaired cognitive function after perineuronal net degradation in the medial prefrontal cortex. eNeuro 5 (6). doi:https://doi.org/10.1523/eneuro.0253-18. 2018

42. Bukalo O, Schachner M, Dityatev A (2001) Modification of extracellular matrix by enzymatic removal of chondroitin sulfate and by lack of tenascin-R differentially affects several forms of synaptic plasticity in the hippocampus. Neuroscience 104(2):359-369. https://doi.org/10.1016/s0306-4522(01) 00082-3

43. Deidda G, Allegra M, Cerri C, Naskar S, Bony G, Zunino G, Bozzi Y, Caleo M, Cancedda L (2015) Early depolarizing GABA controls critical-period plasticity in the rat visual cortex. Nat Neurosci 18(1):87-96. https://doi.org/10.1038/nn.3890

44. Hanover JL, Huang ZJ, Tonegawa S, Stryker MP (1999) Brainderived neurotrophic factor overexpression induces precocious critical period in mouse visual cortex. J Neurosci 19 (22):Rc40. doi:https://doi.org/10.1523/JNEUROSCI.19-22-j0003.1999

45. Huang ZJ, Kirkwood A, Pizzorusso T, Porciatti V, Morales B, Bear MF, Maffei L, Tonegawa S (1999) BDNF regulates the maturation of inhibition and the critical period of plasticity in mouse visual cortex. Cell 98(6):739-755. https://doi.org/10. 1016/s0092-8674(00)81509-3

46. Bramham CR, Messaoudi E (2005) BDNF function in adult synaptic plasticity: the synaptic consolidation hypothesis. Prog Neurobiol 76(2):99-125. https://doi.org/10.1016/j.pneurobio. 2005.06.003

47. Guilding C, McNair K, Stone TW, Morris BJ (2007) Restored plasticity in a mouse model of neurofibromatosis type 1 via 
inhibition of hyperactive ERK and CREB. Eur J Neurosci 25(1):99-105. https://doi.org/10.1111/j.1460-9568.2006.05238.x

48. Warren PM, Andrews MR, Smith M, Bartus K, Bradbury EJ, Verhaagen J, Fawcett JW, Kwok JCF (2020) Secretion of a mammalian chondroitinase $\mathrm{ABC}$ aids glial integration at PNS/ CNS boundaries. Sci Rep 10(1):11262. https://doi.org/10.1038/ s41598-020-67526-0

49. Johnston GAR (2013) Advantages of an antagonist: bicuculline and other GABA antagonists. Br J Pharmacol 169(2):328-336. https://doi.org/10.1111/bph.12127

50. Kasteel EEJ, Westerink RHS (2017) Comparison of the acute inhibitory effects of Tetrodotoxin (TTX) in rat and human neuronal networks for risk assessment purposes. Toxicol Lett 270:12-16. https://doi.org/10.1016/j.toxlet.2017.02.014

51. Telese F, Ma Q, Perez PM, Notani D, Oh S, Li W, Comoletti D, Ohgi KA, Taylor H, Rosenfeld MG (2015) LRP8-reelinregulated neuronal enhancer signature underlying learning and memory formation. Neuron 86(3):696-710. https://doi.org/10. 1016/j.neuron.2015.03.033

52. Strata F, Cherubini E (1994) Transient expression of a novel type of GABA response in rat CA3 hippocampal neurones during development. The Journal of physiology 480 ( Pt 3) (Pt 3):493503. doi:https://doi.org/10.1113/jphysiol.1994.sp020378

53. Zhou X, Moon C, Zheng F, Luo Y, Soellner D, Nuñez JL, Wang H (2009) N-methyl-D-aspartate-stimulated ERK1/2 signaling and the transcriptional up-regulation of plasticity-related genes are developmentally regulated following in vitro neuronal maturation. J Neurosci Res 87(12):2632-2644. https://doi.org/10. 1002/jnr.22103

54. Kim MJ, Futai K, Jo J, Hayashi Y, Cho K, Sheng M (2007) Synaptic accumulation of PSD-95 and synaptic function regulated by phosphorylation of serine-295 of PSD-95. Neuron 56(3):488-502

55. Vashishta A, Habas A, Pruunsild P, Zheng J-J, Timmusk T, Hetman M (2009) Nuclear factor of activated T-cells isoform c4 (NFATc4/NFAT3) as a mediator of antiapoptotic transcription in NMDA receptor-stimulated cortical neurons. J Neurosci 29(48):15331-15340. https://doi.org/10.1523/jneurosci.4873-09. 2009

56. Das S, Moon HC, Singer RH, Park HY (2018) A transgenic mouse for imaging activity-dependent dynamics of endogenous Arc mRNA in live neurons. Sci Adv 4 (6):eaar3448-eaar3448. doi:https://doi.org/10.1126/sciadv.aar3448

57. Giacomini C, Koo CY, Yankova N, Tavares IA, Wray S, Noble W, Hanger DP, Morris JDH (2018) A new TAO kinase inhibitor reduces tau phosphorylation at sites associated with neurodegeneration in human tauopathies. Acta Neuropathol Commun 6(1):37. https://doi.org/10.1186/s40478-018-0539-8

58. Koo CY, Giacomini C, Reyes-Corral M, Olmos Y, Tavares IA, Marson CM, Linardopoulos S, Tutt AN, Morris JDH (2017) Targeting TAO kinases using a new inhibitor compound delays mitosis and induces mitotic cell death in centrosome amplified breast cancer cells. Mol Cancer Ther 16(11):2410-2421. https:// doi.org/10.1158/1535-7163.Mct-17-0077

59. Yamada MK, Nakanishi K, Ohba S, Nakamura T, Ikegaya Y, Nishiyama N, Matsuki N (2002) Brain-derived neurotrophic factor promotes the maturation of GABAergic mechanisms in cultured hippocampal neurons. J Neurosci 22(17):7580-7585. https://doi.org/10.1523/jneurosci.22-17-07580.2002

60. Miyata S, Nadanaka S, Igarashi M, Kitagawa H (2018) Structural variation of chondroitin sulfate chains contributes to the molecular heterogeneity of perineuronal nets. Front Integr Neurosci 12:3-3. https://doi.org/10.3389/fnint.2018.00003

61. Willis A, Pratt JA, Morris BJ (2018) Distortion of protein analysis in primary neuronal cultures by serum albumin from culture medium: a methodological approach to improve target protein quantification. J Neurosci Methods 308:1-5. https://doi.org/10. 1016/j.jneumeth.2018.07.002

62. Bradford MM (1976) A rapid and sensitive method for the quantitation of microgram quantities of protein utilizing the principle of protein-dye binding. Anal Biochem 72(1):248-254. https:// doi.org/10.1016/0003-2697(76)90527-3

63. McDonald AJ, Mascagni F (2006) Differential expression of $\mathrm{Kv} 3.1 \mathrm{~b}$ and $\mathrm{Kv} 3.2$ potassium channel subunits in interneurons of the basolateral amygdala. Neuroscience 138 (2):537-547. doi: https://doi.org/10.1016/j.neuroscience.2005.11.047

64. Hedstrom KL, Xu X, Ogawa Y, Frischknecht R, Seidenbecher CI, Shrager P, Rasband MN (2007) Neurofascin assembles a specialized extracellular matrix at the axon initial segment. J Cell Biol 178(5):875-886. https://doi.org/10.1083/jcb.200705119

65. John N, Krügel H, Frischknecht R, Smalla K-H, Schultz C, Kreutz MR, Gundelfinger ED, Seidenbecher CI (2006) Brevican-containing perineuronal nets of extracellular matrix in dissociated hippocampal primary cultures. Mol Cell Neurosci 31(4):774-784. https://doi.org/10.1016/j.mcn.2006.01.011

66. Kawashima T, Okuno H, Bito H (2014) A new era for functional labeling of neurons: activity-dependent promoters have come of age. Frontiers in Neural Circuits 8 (37). doi:https://doi.org/10. 3389/fncir.2014.00037

67. Gary SC, Zerillo CA, Chiang VL, Gaw JU, Gray G, Hockfield S (2000) cDNA cloning, chromosomal localization, and expression analysis of human BEHAB/brevican, a brain specific proteoglycan regulated during cortical development and in glioma. Gene 256(1):139-147. https://doi.org/10.1016/S0378-1119(00) 00362-0

68. Gary SC, Kelly GM, Hockfield S (1998) BEHAB/brevican: a brain-specific lectican implicated in gliomas and glial cell motility. Curr Opin Neurobiol 8(5):576-581. https://doi.org/10.1016/ S0959-4388(98)80083-4

69. Fowke TM, Karunasinghe RN, Bai JZ, Jordan S, Gunn AJ, Dean JM (2017) Hyaluronan synthesis by developing cortical neurons in vitro. Sci Rep 7:44135. https://doi.org/10.1038/srep44135

70. Coffey ET (2014) Nuclear and cytosolic JNK signalling in neurons. Nat Rev Neurosci 15(5):285-299. https://doi.org/10.1038/ nrn3729

71. Coffey ET, Hongisto V, Dickens M, Davis RJ, Courtney MJ (2000) Dual roles for c-Jun N-terminal kinase in developmental and stress responses in cerebellar granule neurons. J Neurosci 20(20):7602-7613. https://doi.org/10.1523/jneurosci.20-2007602.2000

72. Myers AK, Cunningham JG, Smith SE, Snow JP, Smoot CA, Tucker ES (2020) JNK signaling is required for proper tangential migration and laminar allocation of cortical interneurons. Development 147 (2):dev180646. doi:https://doi.org/10.1242/ dev.180646

73. Myers AK, Meechan DW, Adney DR, Tucker ES (2014) Cortical interneurons require Jnk1 to enter and navigate the developing cerebral cortex. J Neurosci 34(23):7787-7801. https://doi.org/ 10.1523/JNEUROSCI.4695-13.2014

74. Riches JJ, Reynolds K (2014) Jnk1 activity is indispensable for appropriate cortical interneuron migration in the developing cerebral cortex. J Neurosci 34(43):14165-14166. https://doi.org/10. 1523/JNEUROSCI.3222-14.2014

75. Kuan CY, Yang DD, Samanta Roy DR, Davis RJ, Rakic P, Flavell RA (1999) The Jnk1 and Jnk2 protein kinases are required for regional specific apoptosis during early brain development. Neuron 22(4):667-676. https://doi.org/10.1016/s0896-6273(00) 80727-8

76. Willis A, Pratt JA, Morris BJ (2020) BDNF and JNK signaling modulate cortical interneuron and perineuronal net development: implications for schizophrenia-linked 16p11.2 duplication 
syndrome. Schizophr Bull. doi:https://doi.org/10.1093/schbul/ sbaa139

77. Rudy B, McBain CJ (2001) Kv3 channels: voltage-gated K+ channels designed for high-frequency repetitive firing. Trends Neurosci 24(9):517-526. https://doi.org/10.1016/s0166-2236(00) 01892-0

78. Gan L, Kaczmarek LK (1998) When, where, and how much? Expression of the Kv3.1 potassium channel in high-frequency firing neurons. J Neurobiol 37 (1):69-79. https://doi.org/10.1002/ (sici)1097-4695(199810)37:1<69::aid-neu6>3.0.co;2-6

79. Milev P, Maurel P, Chiba A, Mevissen M, Popp S, Yamaguchi Y, Margolis RK, Margolis RU (1998) Differential regulation of expression of hyaluronan-binding proteoglycans in developing brain: aggrecan, versican, neurocan, and brevican. Biochem Biophys Res Commun 247(2):207-212. https://doi.org/10.1006/ bbrc. 1998.8759

80. Kim EJ, Leung CT, Reed RR, Johnson JE (2007) In vivo analysis of Ascl1 defined progenitors reveals distinct developmental dynamics during adult neurogenesis and gliogenesis. J Neurosci 27(47):12764-12774. https://doi.org/10.1523/jneurosci. 3178-07.2007

81. Nakatani H, Martin E, Hassani H, Clavairoly A, Maire CL, Viadieu A, Kerninon C, Delmasure A, Frah M, Weber M, Nakafuku M, Zalc B, Thomas JL, Guillemot F, Nait-Oumesmar B, Parras C (2013) Ascl1/Mash1 promotes brain oligodendrogenesis during myelination and remyelination. J Neurosci 33(23):9752-9768. https://doi.org/10.1523/jneurosci.0805-13. 2013

82. Cobos I, Borello U, Rubenstein JL (2007) Dlx transcription factors promote migration through repression of axon and dendrite growth. Neuron 54(6):873-888. https://doi.org/10.1016/j.neuron. 2007.05.024

83. Pla R, Stanco A, Howard MA, Rubin AN, Vogt D, Mortimer N, Cobos I, Potter GB, Lindtner S, Price JD, Nord AS, Visel A, Schreiner CE, Baraban SC, Rowitch DH, Rubenstein JLR (2018) Dlx 1 and Dlx 2 promote interneuron GABA synthesis, synaptogenesis, and dendritogenesis. Cereb Cortex 28(11):3797-3815. https://doi.org/10.1093/cercor/bhx241

84. Le TN, Zhou QP, Cobos I, Zhang S, Zagozewski J, Japoni S, Vriend J, Parkinson T, Du G, Rubenstein JL, Eisenstat DD (2017) GABAergic interneuron differentiation in the basal forebrain is mediated through direct regulation of glutamic acid decarboxylase isoforms by Dlx homeobox transcription factors. J Neurosci 37(36):8816-8829. https://doi.org/10.1523/jneurosci.2125-16. 2017

85. Okaty BW, Miller MN, Sugino K, Hempel CM, Nelson SB (2009) Transcriptional and electrophysiological maturation of neocortical fast-spiking GABAergic interneurons. J Neurosci 29(21):7040-7052. https://doi.org/10.1523/JNEUROSCI.010509.2009

86. Favuzzi E, Marques-Smith A, Deogracias R, Winterflood CM, Sánchez-Aguilera A, Mantoan L, Maeso P, Fernandes C, Ewers H, Rico B (2017) Activity-dependent gating of parvalbumin interneuron function by the perineuronal net protein brevican. Neuron 95(3):639-655.e610. https://doi.org/10.1016/j.neuron. 2017.06.028

87. Hevner RF, Hodge RD, Daza RAM, Englund C (2006) Transcription factors in glutamatergic neurogenesis: conserved programs in neocortex, cerebellum, and adult hippocampus. Neurosci Res 55(3):223-233. https://doi.org/10.1016/j.neures.2006.03.004

88. Bel-Vialar S, Medevielle F, Pituello F (2007) The on/off of Pax6 controls the tempo of neuronal differentiation in the developing spinal cord. Dev Biol 305(2):659-673. https://doi.org/10.1016/j. ydbio.2007.02.012

89. Osumi N, Kikkawa T (2013) The role of the transcription factor Pax6 in brain development and evolution: evidence and hypothesis. In: Kageyama R, Yamamori T (eds) Cortical development: neural diversity and neocortical organization. Springer Japan, Tokyo, pp 43-61. doi:https://doi.org/10.1007/ 978-4-431-54496-8_3

90. Chu P, Abraham R, Budhu K, Khan U, De Marco GN, Brumberg JC (2018) The impact of perineuronal net digestion using chondroitinase $\mathrm{ABC}$ on the intrinsic physiology of cortical neurons. Neuroscience 388:23-35. https://doi.org/10.1016/j.neuroscience. 2018.07.004

91. Mitlöhner J, Kaushik R, Niekisch H, Blondiaux A, Gee CE, Happel MFK, Gundelfinger E, Dityatev A, Frischknecht R, Seidenbecher C (2020) Dopamine receptor activation modulates the integrity of the perisynaptic extracellular matrix at excitatory synapses. Cells 9 (2). doi:https://doi.org/10.3390/cells9020260

92. de Lecea L, del Río JA, Soriano E (1995) Developmental expression of parvalbumin mRNA in the cerebral cortex and hippocampus of the rat. Brain Res Mol Brain Res 32(1):1-13. https://doi. org/10.1016/0169-328x(95)00056-x

93. Chattopadhyaya B, Di Cristo G, Higashiyama H, Knott GW, KuhIman SJ, Welker E, Huang ZJ (2004) Experience and activitydependent maturation of perisomatic GABAergic innervation in primary visual cortex during a postnatal critical period. The Journal of neuroscience : the official journal of the Society for Neuroscience 24(43):9598-9611. https://doi.org/10.1523/JNEUR OSCI.1851-04.2004

94. Cisneros-Franco JM, de Villers-Sidani É (2019) Reactivation of critical period plasticity in adult auditory cortex through chemogenetic silencing of parvalbumin-positive interneurons. Proc Natl Acad Sci U S A 116(52):26329-26331. https://doi.org/10.1073/ pnas. 1913227117

95. Patz S, Grabert J, Gorba T, Wirth MJ, Wahle P (2004) Parvalbumin expression in visual cortical interneurons depends on neuronal activity and TrkB ligands during an early period of postnatal development. Cereb Cortex 14(3):342-351. https://doi. org/10.1093/cercor/bhg132

96. Philpot BD, Lim JH, Brunjes PC (1997) Activity-dependent regulation of calcium-binding proteins in the developing rat olfactory bulb. Journal of Comparative Neurology 387(1):1226. https://doi.org/10.1002/(SICI)1096-9861(19971013)387:1\% 3c12::AID-CNE2\%3e3.0.CO;2-Q

97. Tropea D, Kreiman G, Lyckman A, Mukherjee S, Yu H, Horng S, Sur M (2006) Gene expression changes and molecular pathways mediating activity-dependent plasticity in visual cortex. Nat Neurosci 9(5):660-668. https://doi.org/10.1038/nn1689

98. Xu JC, Xiao MF, Jakovcevski I, Sivukhina E, Hargus G, Cui YF, Irintchev A, Schachner M, Bernreuther C (2014) The extracellular matrix glycoprotein tenascin-R regulates neurogenesis during development and in the adult dentate gyrus of mice. J Cell Sci 127(Pt 3):641-652. https://doi.org/10.1242/jcs. 137612

99. Brückner G, Grosche J, Schmidt S, Härtig W, Margolis RU, Delpech B, Seidenbecher CI, Czaniera R, Schachner M (2000) Postnatal development of perineuronal nets in wild-type mice and in a mutant deficient in tenascin-R. J Comp Neurol 428(4):616629. https://doi.org/10.1002/1096-9861(20001225)428:4<616:: AID-CNE3>3.0.CO;2-K

100. Xue M, Atallah BV, Scanziani M (2014) Equalizing excitation-inhibition ratios across visual cortical neurons. Nature 511(7511):596-600. https://doi.org/10.1038/nature13321

101. Ferguson BR, Gao WJ (2018) PV interneurons: critical regulators of E/I balance for prefrontal cortex-dependent behavior and psychiatric disorders. Front Neural Circ 12:37. https://doi.org/ 10.3389/fncir.2018.00037

102. Toader O, von Heimendahl M, Schuelert N, Nissen W, Rosenbrock H (2020) Suppression of parvalbumin interneuron activity in the prefrontal cortex recapitulates features of impaired excitatory/inhibitory balance and sensory processing in schizophrenia. 
Schizophr Bull 46(4):981-989. https://doi.org/10.1093/schbul/ sbz123

103. Pfeffer CK, Xue M, He M, Huang ZJ, Scanziani M (2013) Inhibition of inhibition in visual cortex: the logic of connections between molecularly distinct interneurons. Nat Neurosci 16(8):1068-1076. https://doi.org/10.1038/nn.3446

104. Gu Y, Barry J, McDougel R, Terman D, Gu C (2012) Alternative splicing regulates kv3.1 polarized targeting to adjust maximal spiking frequency. J Biol Chem 287 (3):1755-1769. doi:https:// doi.org/10.1074/jbc.M111.299305

105. Kaczmarek LK, Bhattacharjee A, Desai R, Gan L, Song P, von Hehn CA, Whim MD, Yang B (2005) Regulation of the timing of MNTB neurons by short-term and long-term modulation of potassium channels. Hear Res 206(1-2):133-145. https://doi.org/ 10.1016/j.heares.2004.11.023

106. Plotkin JL, Wu N, Chesselet M-F, Levine MS (2005) Functional and molecular development of striatal fast-spiking GABAergic interneurons and their cortical inputs. Eur J Neurosci 22(5):1097-1108. https://doi.org/10.1111/j.1460-9568.2005. 04303.x

107. Berghuis P, Dobszay MB, Sousa KM, Schulte G, Mager PP, Härtig W, Görcs TJ, Zilberter Y, Ernfors P, Harkany T (2004) Brain-derived neurotrophic factor controls functional differentiation and microcircuit formation of selectively isolated fast-spiking GABAergic interneurons. Eur J Neurosci 20(5):1290-1306. https://doi.org/10.1111/j.1460-9568.2004.03561.x

108. Lensjø KK, Lepperød ME, Dick G, Hafting T, Fyhn M (2017) Removal of perineuronal nets unlocks juvenile plasticity through network mechanisms of decreased inhibition and increased gamma activity. J Neurosci 37(5):1269-1283. https://doi.org/ 10.1523/jneurosci.2504-16.2016

109. Frischknecht R, Heine M, Perrais D, Seidenbecher CI, Choquet D, Gundelfinger ED (2009) Brain extracellular matrix affects AMPA receptor lateral mobility and short-term synaptic plasticity. Nat Neurosci 12(7):897-904. https://doi.org/10.1038/nn.2338

110. Dityatev A, Schachner M, Sonderegger P (2010) The dual role of the extracellular matrix in synaptic plasticity and homeostasis. Nat Rev Neurosci 11(11):735-746. https://doi.org/10.1038/nrn28 98

111. Benson DL, Watkins FH, Steward O, Banker G (1994) Characterization of GABAergic neurons in hippocampal cell cultures. J Neurocytol 23(5):279-295. https://doi.org/10.1007/BF01188497

112. Chung L (2015) A Brief Introduction to the Transduction of Neural Activity into Fos Signal. Dev Reprod 19(2):61-67. https://doi. org/10.12717/DR.2015.19.2.061

113. Beique JC, Na Y, Kuhl D, Worley PF, Huganir RL (2011) Arcdependent synapse-specific homeostatic plasticity. Proc Natl Acad Sci U S A 108(2):816-821. https://doi.org/10.1073/pnas. 1017914108

114. Osumi N, Shinohara H, Numayama-Tsuruta K, Maekawa M (2008) Concise review: Pax6 transcription factor contributes to both embryonic and adult neurogenesis as a multifunctional regulator. Stem Cells 26(7):1663-1672. https://doi.org/10.1634/ stemcells.2007-0884

115. Sibbe M, Kulik A (2017) GABAergic regulation of adult hippocampal neurogenesis. Mol Neurobiol 54(7):5497-5510. https://doi.org/10.1007/s12035-016-0072-3

116. Lander C, Kind P, Maleski M, Hockfield S (1997) A family of activity-dependent neuronal cell-surface chondroitin sulfate proteoglycans in cat visual cortex. J Neurosci 17(6):1928-1939. https://doi.org/10.1523/jneurosci.17-06-01928.1997

117. McRae PA, Rocco MM, Kelly G, Brumberg JC, Matthews RT (2007) Sensory deprivation alters aggrecan and perineuronal net expression in the mouse barrel cortex. J Neurosci 27(20):54055413. https://doi.org/10.1523/jneurosci.5425-06.2007
118. Lee H, McKeon RJ, Bellamkonda RV (2010) Sustained delivery of thermostabilized chABC enhances axonal sprouting and functional recovery after spinal cord injury. Proc Natl Acad Sci U S A 107(8):3340-3345. https://doi.org/10.1073/pnas.0905437106

119. Bradbury EJ, Moon LD, Popat RJ, King VR, Bennett GS, Patel PN, Fawcett JW, McMahon SB (2002) Chondroitinase ABC promotes functional recovery after spinal cord injury. Nature 416(6881):636-640. https://doi.org/10.1038/416636a

120. Smith S, Coker N, Tucker E (2020) JNK signaling controls branching, nucleokinesis, and positioning of centrosomes and primary cilia in migrating cortical interneurons. bioRxiv. https:// doi.org/10.1101/2020.01.30.927855

121. Komulainen E, Varidaki A, Kulesskaya N, Mohammad H, Sourander C, Rauvala H, Coffey ET (2020) Impact of JNK and its substrates on dendritic spine morphology. Cells 9 (2). https:// doi.org/10.3390/cells9020440

122. Li XM, Li CC, Yu SS, Chen JT, Sabapathy K, Ruan DY (2007) JNK1 contributes to metabotropic glutamate receptor-dependent long-term depression and short-term synaptic plasticity in the mice area hippocampal CA1. Eur J Neurosci 25(2):391-396. https://doi.org/10.1111/j.1460-9568.2006.05300.x

123. Chen JT, Lu DH, Chia CP, Ruan DY, Sabapathy K, Xiao ZC (2005) Impaired long-term potentiation in c-Jun N-terminal kinase 2-deficient mice. J Neurochem 93(2):463-473. https:// doi.org/10.1111/j.1471-4159.2005.03037.x

124. Sherrin T, Blank T, Hippel C, Rayner M, Davis RJ, Todorovic C (2010) Hippocampal c-Jun-N-terminal kinases serve as negative regulators of associative learning. J Neurosci 30(40):1334813361. https://doi.org/10.1523/jneurosci.3492-10.2010

125. Tararuk T, Ostman N, Li W, Björkblom B, Padzik A, Zdrojewska J, Hongisto V, Herdegen T, Konopka W, Courtney MJ, Coffey ET (2006) JNK1 phosphorylation of SCG10 determines microtubule dynamics and axodendritic length. J Cell Biol 173(2):265-277. https://doi.org/10.1083/jcb.200511055

126. Bartkowska K, Paquin A, Gauthier AS, Kaplan DR, Miller FD (2007) Trk signaling regulates neural precursor cell proliferation and differentiation during cortical development. Development 134(24):4369-4380. https://doi.org/10.1242/dev.008227

127. Kohara K, Yasuda H, Huang Y, Adachi N, Sohya K, Tsumoto T (2007) A local reduction in cortical GABAergic synapses after a loss of endogenous brain-derived neurotrophic factor, as revealed by single-cell gene knock-out method. J Neurosci 27(27):72347244. https://doi.org/10.1523/jneurosci.1943-07.2007

128. Kim DH, Kim JM, Park SJ, Cai M, Liu X, Lee S, Shin CY, Ryu JH (2012) GABA(A) receptor blockade enhances memory consolidation by increasing hippocampal BDNF levels. Neuropsychopharmacology 37(2):422-433. https://doi.org/10.1038/npp. 2011.189

129. Naderipoor P, Amani M, Abedi A, Sakhaie N, Sadegzadeh F, Saadati H (2021) Alterations in the behavior, cognitive function, and BDNF level in adult male rats following neonatal blockade of GABA-A receptors. Brain Res Bull 169:35-42. https://doi.org/ 10.1016/j.brainresbull.2021.01.006

130. Shelly M, Cancedda L, Lim BK, Popescu AT, Cheng P-1, Gao H, Poo M-m (2011) Semaphorin3A regulates neuronal polarization by suppressing axon formation and promoting dendrite growth. Neuron 71(3):433-446. https://doi.org/10.1016/j.neuron.2011. 06.041

131. Morita A, Yamashita N, Sasaki Y, Uchida Y, Nakajima O, Nakamura F, Yagi T, Taniguchi M, Usui H, Katoh-Semba R, Takei K, Goshima Y (2006) Regulation of dendritic branching and spine maturation by semaphorin3A-Fyn signaling. J Neurosci 26(11):2971-2980. https://doi.org/10.1523/jneurosci.5453-05. 2006

132. Mohan V, Wyatt EV, Gotthard I, Phend KD, Diestel S, Duncan BW, Weinberg RJ, Tripathy A, Maness PF (2018) Neurocan 
inhibits semaphorin $3 \mathrm{~F}$ induced dendritic spine remodeling through NrCAM in cortical neurons. Frontiers in Cellular Neuroscience 12 (346). https://doi.org/10.3389/fncel.2018.00346

133. Akita K, Toda M, Hosoki Y, Inoue M, Fushiki S, Oohira A, Okayama M, Yamashina I, Nakada H (2004) Heparan sulphate proteoglycans interact with neurocan and promote neurite outgrowth from cerebellar granule cells. Biochem J 383(Pt 1):129138. https://doi.org/10.1042/bj20040585

134. de Anda FC, Rosario AL, Durak O, Tran T, Gräff J, Meletis K, Rei D, Soda T, Madabhushi R, Ginty DD, Kolodkin AL, Tsai LH (2012) Autism spectrum disorder susceptibility gene TAOK2 affects basal dendrite formation in the neocortex. Nat Neurosci 15(7):1022-1031. https://doi.org/10.1038/nn.3141

135. Richter M, Murtaza N, Scharrenberg R, White SH, Johanns O, Walker S, Yuen RKC, Schwanke B, Bedürftig B, Henis M, Scharf S, Kraus V, Dörk R, Hellmann J, Lindenmaier Z, Ellegood J, Hartung H, Kwan V, Sedlacik J, Fiehler J, Schweizer M, Lerch JP, Hanganu-Opatz IL, Morellini F, Scherer SW, Singh KK, Calderon de Anda F (2019) Altered TAOK2 activity causes autismrelated neurodevelopmental and cognitive abnormalities through RhoA signaling. Mol Psychiatry 24(9):1329-1350. https://doi. org/10.1038/s41380-018-0025-5

136. Giaroli G, Bass N, Strydom A, Rantell K, McQuillin A (2014) Does rare matter? Copy number variants at $16 \mathrm{p} 11.2$ and the risk of psychosis: a systematic review of literature and meta-analysis. Schizophr Res 159 (2-3):340-346. https://doi.org/10.1016/j. schres.2014.09.025

137. Kirov G, Rees E, Walters JT, Escott-Price V, Georgieva L, Richards AL, Chambert KD, Davies G, Legge SE, Moran JL, McCarroll SA, O'Donovan MC, Owen MJ (2014) The penetrance of copy number variations for schizophrenia and developmental delay. Biol Psychiatry 75(5):378-385. https://doi.org/10.1016/j. biopsych.2013.07.022

138. Weiss LA, Shen Y, Korn JM, Arking DE, Miller DT, Fossdal R, Saemundsen E, Stefansson H, Ferreira MA, Green T, Platt OS, Ruderfer DM, Walsh CA, Altshuler D, Chakravarti A, Tanzi RE, Stefansson K, Santangelo SL, Gusella JF, Sklar P, Wu BL, Daly MJ (2008) Association between microdeletion and microduplication at 16p11.2 and autism. N Engl J Med 358 (7):667-675. https://doi.org/10.1056/NEJMoa075974

Publisher's Note Springer Nature remains neutral with regard to jurisdictional claims in published maps and institutional affiliations. 